\title{
EL COMPORTAMIENTO MORTUORIO DE LOS CAZADORES RECOLECTORES DEL SITIO MÉDANO PETROQUÍMICA (LA PAMPA, ARGENTINA). CARACTERIZACIÓN PRELIMINAR DESDE UN ABORDAJE TAFONÓMICO
}

\author{
MORTUARY BEHAVIOR OF THE HUNTER GATHERERS FROM MÉDANO \\ PETROQUÍMICA SITE (LA PAMPA, ARGENTINA). PRELIMINARY \\ CHARACTERIZATION FROM A TAPHONOMIC APPROACH
}

Melina C. Bottini ${ }^{1}$, Mario A. Arrieta ${ }^{1,2}$ y Lila Bernardi ${ }^{1,2}$

\begin{abstract}
En este trabajo se propone la utilización de herramientas provenientes de la tafonomía y la arqueotanatología para ampliar el conocimiento sobre las costumbres mortuorias y los procesos de formación de sitio a partir del análisis de restos óseos humanos. La muestra proviene del sitio Médano Petroquímica, un área de inhumación ubicada al sudoeste de la provincia de La Pampa, Argentina, que habría sido originada por sociedades cazadoras recolectoras de finales del Holoceno Tardío. Los resultados obtenidos del estudio de cuatro entierros, uno primario y tres secundarios (NMI=19), sugieren que las huellas de corte y la permanencia de relaciones articulares son consistentes con prácticas de manipulación del cuerpo en diferentes momentos después de la muerte. Por su parte, la actividad de insectos se registró en mayor frecuencia en el entierro primario. Los fechados, junto con la presencia de insectos, ocre y las características específicas de cada rasgo soportarían mayormente la sincronía en la inhumación de los rasgos del sitio.
\end{abstract}

Palabras claves: tafonomía humana, cazadores recolectores, prácticas mortuorias, huellas de corte, fracturas perimortem.

This paper proposes the use of analytical tools from taphonomy and archaeothanatology to expand knowledge about mortuary customs and site formation processes from the analysis of human bone remains. The sample comes from the Médano Petroquímica site, an inhumation area located south west of La Pampa province, Argentina, which would have been originated by hunter-gatherer societies from the Late Holocene. The results obtained from the study of four burials, one primary and three secondary $(N M I=19)$, suggest that the cut-marks and the presence of articular relationships are consistent with practices of body manipulation at different times after death. Furthermore, a greater frequency of insects activity was recorded in the primary burial. The radiocarbon dates, along with the presence of insects, ocher, and the specific features of each burial, would largely support the synchrony in the inhumation of the features of the site.

Key words: Human Taphonomy, hunter gatherers, mortuary practices, cut-marks, perimortem fractures.

El comportamiento mortuorio en las sociedades del pasado ha sido objeto de interés ya desde el siglo XIX (Cushing 1890; Hinsley y Wilcox 1996). Algunos autores remarcan que los contextos funerarios reflejarían el estadio final de una larga y compleja secuencia de rituales de enterramiento (Binford 1971; Brown 1981; Saxe 1971).

Por otro lado, los estudios tafonómicos pueden proporcionarnos sólidos indicios acerca de los distintos procesos que operaron en la formación de sitios (Stodder 2008), permitiéndonos discriminar entre aquellos de origen natural y los de origen antrópico (Fisher 1995).
De este modo, por medio de la utilización conjunta de la información proporcionada tanto por el análisis osteológico como por los datos de campo se pueden realizar inferencias acerca de las historias tafonómicas de los conjuntos arqueológicos (Duday y Guillon 2006; Duday et al. 2014; Stodder 2008). Si bien el número de agentes y procesos que pueden actuar sobre un cuerpo desde el momento de su muerte puede ser cuantioso, generalmente las prácticas mortuorias son los factores mayormente determinantes de las condiciones de hallazgo de restos humanos (Henderson 1987).

\footnotetext{
${ }^{1}$ Laboratorio Bioarqueología, Facultad de Ciencias Exactas, Físico-Químicas y Naturales, Universidad Nacional de Río Cuarto, Córdoba, Argentina.mbottini@exa.unrc.edu.ar; marrieta@exa.unrc.edu.ar; lbernardi@exa.unrc.edu.ar

${ }^{2}$ CONICET-Consejo Nacional de Investigaciones Científicas y Técnicas, Buenos Aires, Argentina.
}

Recibido: abril 2019. Aceptado: octubre 2019.

http://dx.doi.org/10.4067/S0717-73562020005000901. Publicado en línea: 16-junio-2020. 
En Argentina, mediante la utilización de diversas fuentes de información (análisis cuantitativos, tafonómicos y de campo) se han realizado multitud de estudios con el objeto de comprender y ampliar el conocimiento de diversos rituales relacionados con la muerte y la formación de sitios arqueológicos (Barrientos y Gutiérrez 1996; Berón et al. 2012; González 2007, 2013, 2014; Martínez et al. 2006; Tavarone et al. 2016). En este punto, las sociedades cazadoras-recolectoras de la región Pampa-Patagonia, las cuales se caracterizan por haber desarrollado la práctica de entierros secundarios, han despertado un especial interés en los investigadores del pasado. En estas sociedades, la planificación de los programas mortuorios, que implicaban la manipulación de los cuerpos, pone de manifiesto una compleja organización que tendría como finalidad la realización de actividades tales como el descarne, la desarticulación, el reordenamiento de los restos esqueléticos, la coloración y la preparación de los paquetes funerarios, como también la recuperación de los restos de entierros primarios y el transporte de los paquetes hacia su destino final en lugares particulares del paisaje (Flensborg et al. 2017). Aunque los entierros secundarios de la región datan de aproximadamente del 7600 AP (Politis et al. 2014; Scabuzzo y Politis 2011), se ha propuesto que durante el Holoceno Tardío (800250 años AP) estas sociedades habrían sufrido severos cambios en su organización (i.e., marcado aumento demográfico, reducción de la movilidad y ocupación de todas las áreas dentro de la región (Berón y Politis 1997; Madrid y Barrientos 2000; Martínez 2006; Mazzanti y
Quintana 2001)) que podrían haber sido la causa de la aparición de sitios formales de entierro y, sobre todo, de entierros secundarios (Flensborg et al. 2017; Martínez 2017).

Para el estudio de prácticas mortuorias en poblaciones cazadoras-recolectoras prehispánicas de esta región, algunos investigadores se han enfocado en el análisis de huellas de cortes producidas por instrumentos filosos (González 2010), otros han utilizado el análisis de restos de tejidos hallados en entierros para abordar el estudio de la formación y confección de los paquetes mortuorios (Berón et al. 2012) y, finalmente, se han realizado análisis de la posición de los elementos óseos en el registro bioarqueológico para realizar inferencias sobre el manejo de cuerpos, utilizando además la información proporcionada por el registro etnográfico (Berón et al. 2012; Flensborg et al. 2017; Martínez et al. 2006, 2012).

\section{El Sitio Médano Petroquímica}

El sitio Médano Petroquímica (MP) es un área exclusiva de entierros prehispánicos que se ubica en una estructura medanosa de origen eólico y se caracteriza por la presencia de rasgos funerarios con una alta densidad de individuos inhumados. Se localiza aproximadamente a $30 \mathrm{~km}$ al sur de Colonia 25 de Mayo y a $2 \mathrm{~km}$ de la costa este del Río Colorado, en el sudoeste de la provincia de La Pampa (Figura 1.A). El médano se encuentra entre los 340 y 360 msm y

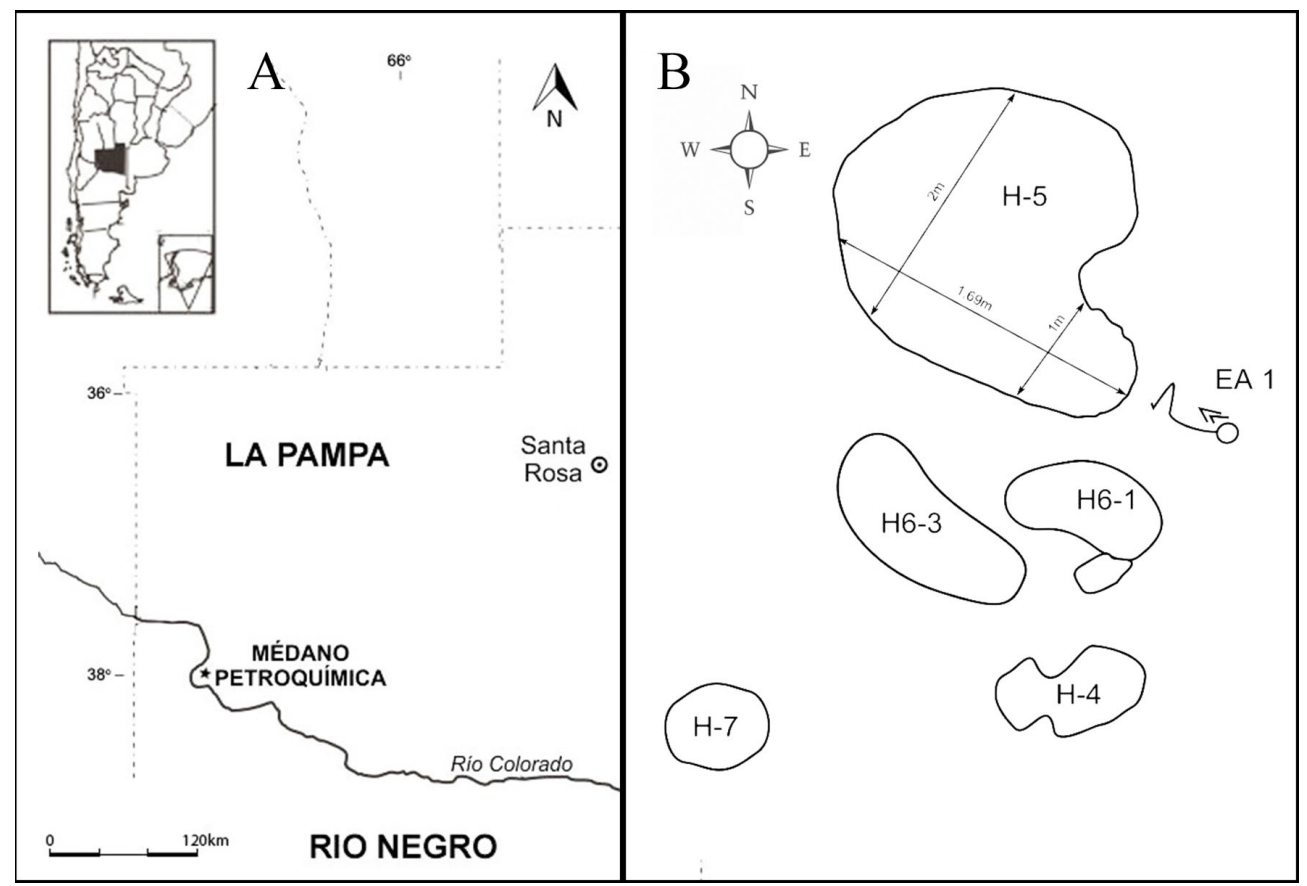

Figura 1. A: Localización del sitio MP. B: Disposición de los rasgos en el médano.

A: Location of the MP site. B: Arrangement of the burials in the dune. 
se elevaba aproximadamente $3 \mathrm{~m}$ sobre el nivel del terreno. Debido a que fue desprovisto de su cobertura vegetal original, la deflación del sedimento causada por los fuertes vientos característicos de la zona provocó la exposición de los restos óseos allí inhumados. Entre los años 2006 y 2009 se detectaron y excavaron seis rasgos: EA-1, H-4, H5, H6-1, H6-3 y H7 (Figura 1.B), la mayoría de los cuales contenían múltiples individuos. Seis dataciones radiocarbónicas señalan que el sitio habría sido utilizado hacia fines del Holoceno Tardío (Tabla 1).

Varios sitios arqueológicos que se encuentran relativamente cercanos al sitio MP comparten algunas de estas particularidades (i.e., ubicación en estructuras medanosas próximas a fuentes de agua dulce, elevado número de individuos inhumados y la presencia de pigmentos y cuentas de collar elaboradas sobre valvas de molusco). Entre ellos encontramos al sitio Loma de la Lata en Neuquén (Cúneo et al. 2016), los sitios Chenque I (Baffi y Berón 2000; Berón et al. 2012; Berón y Luna 2007; Luna et al. 2004) y Médano La Enriqueta (Carrera Aizpitarte et al. 2013) en la provincia de La Pampa y, en la provincia de Buenos Aires, se encuentran los sitios Laguna Los Chilenos (Barrientos et al. 2002), Campo Brochetto y Napostá
(Barrientos 1997; Barrientos y Leipus 1997), Paso Alsina I (Martínez et al. 2006, 2012; Martínez 20082009, 2010) y La Petrona (Flensborg et al. 2011; Martínez y Figuerero Torres 2000; Martínez 2010; Martínez et al. 2012).

Durante las excavaciones en el MP, dada la necesidad de una recuperación relativamente rápida del material óseo, mucha información contextual no pudo ser registrada. Este hecho dificultó en cierto grado los análisis osteológicos posteriores, pero en el presente trabajo se pretende demostrar algunas de las posibilidades brindadas desde la tafonomía humana para la interpretación de datos provenientes de entierros secundarios (Knüsel y Robb 2016; Roksandic 2002; Stodder 2008).

En base a lo mencionado anteriormente, este trabajo tiene como objetivos presentar nueva información tafonómica del sitio MP y, a partir del análisis de la misma más el uso de otras fuentes de datos, intentar caracterizar algunas prácticas mortuorias llevadas a cabo por las sociedades de cazadores-recolectores del Holoceno Tardío que generaron este sitio. Para ello se pondrá particular énfasis en el análisis de variables directamente vinculadas con el accionar antrópico.

Tabla 1. Fechados radiocarbónicos calibrados del sitio MP.

Calibrated radiocarbon dating of the MP site.

\begin{tabular}{lcccc}
\hline \multicolumn{1}{c}{ Código muestra } & Entierro & Material & Edad C14 AP & Cal AD 2区* \\
\hline AA74041** & No asignado*** & Hueso humano (costilla) & $393 \pm 41$ & $1455-1630$ \\
AA74042** & H4 & Hueso humano(costilla) & $378 \pm 41$ & $419 \pm 46$ \\
AA89803 & H5 & Hueso humano (occipital) & $412 \pm 46$ & $1460-1635$ \\
AA89804 & H6-1 & Hueso humano (temporal) & $411 \pm 47$ \\
AA89805 & H7 & Hueso humano (mandíbula) & $363 \pm 45$ \\
AA89806 & EA-1 & Hueso humano (costilla) & $1448-1627$ \\
\hline
\end{tabular}

* Calibrados con el programa OxCal 4.3 utilizando la curva SHCal13 (Hogg et al. 2013).

** Fechados publicados en Mendonça et al. (2010).

*** La muestra enviada a fechar fue recolectada de la superficie del médano por personal policial.

\section{Materiales y Metodología}

En este trabajo se analizará una muestra esquelética humana proveniente de los rasgos EA1, H4, H6-1 y H7. Los elementos óseos proceden de un entierro primario, el cual fue hallado en completa relación articular (EA-1), y tres entierros que contenían múltiples inhumaciones, las cuales habrían sido ingresadas con diversos grados de articulación (Figura 2). Los tres entierros múltiples tenían cada uno cerca de tres metros de circunferencia, generalmente con los cráneos ubicados más cerca de la superficie y de la periferia de la tumba y con los huesos largos dispuestos longitudinalmente tanto en dirección norte-sur como este-oeste. En las tumbas solamente se hallaron, a modo de inclusiones, cuentas de collar elaboradas sobre conchas de moluscos (las cuales se observaron sobre las capas de sedimento más superficiales), numerosas puntas de flechas líticas y fragmentos de las mismas (varias de ellas incrustadas 
en hueso) y un fragmento de cuenta veneciana de vidrio, que se halló en la base del rasgo $\mathrm{H} 7$. El rasgo H4 contenía 10 individuos, mientras que en el rasgo H6-1 fueron excavados 19 individuos y del rasgo H7 se recuperaron seis individuos (Bernardi 2018).
Los esqueletos actualmente se hallan resguardados en el Laboratorio de Bioarqueología de la Universidad Nacional de Río Cuarto, donde también se llevó a cabo este estudio. Para este trabajo se consideraron únicamente los elementos óseos pertenecientes a

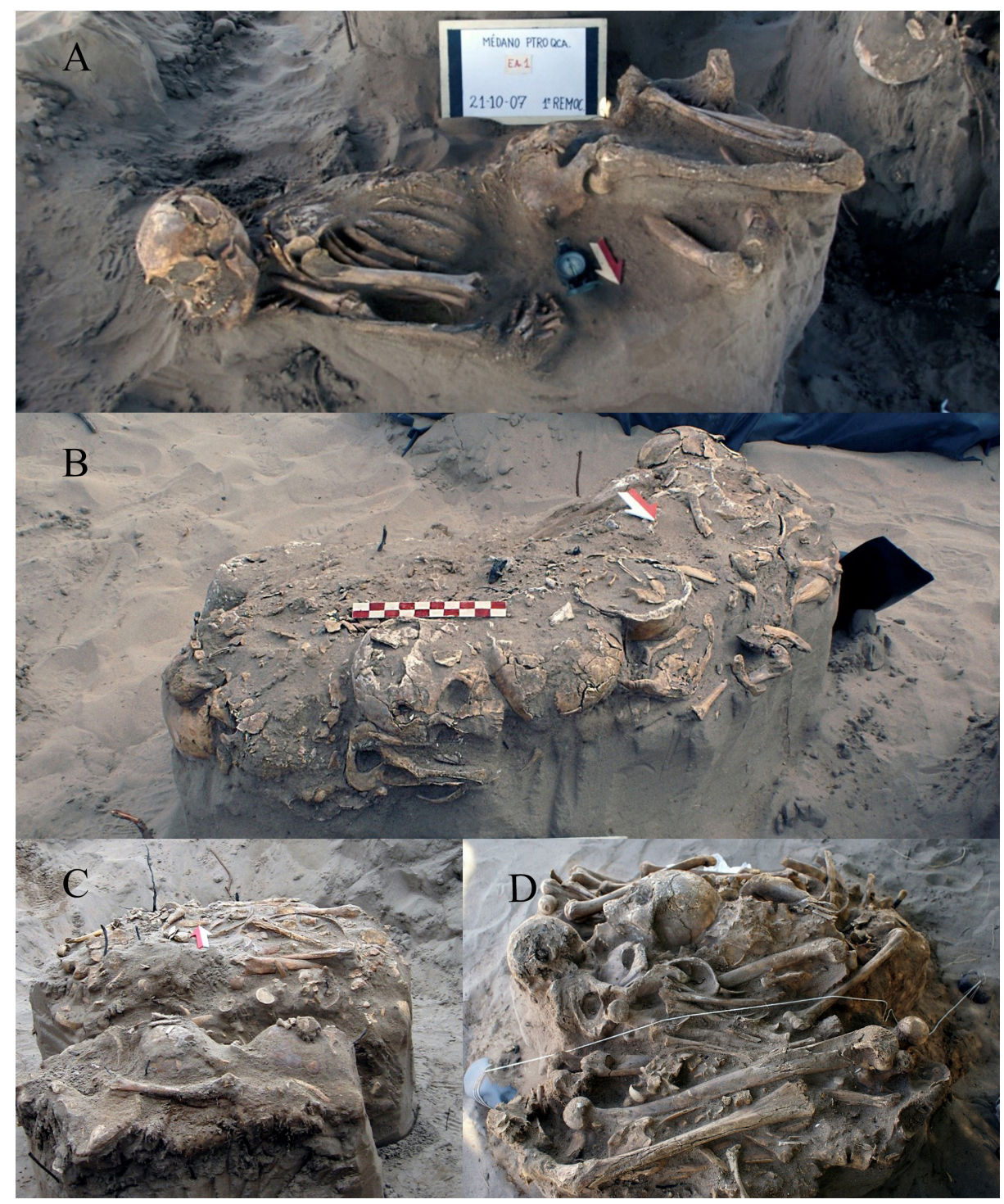

Figura 2. Entierros analizados en este trabajo. A: Vista norte del rasgo EA-1. B: Vista norte del rasgo H6-1 durante la primera remoción. C: Vista sur del rasgo H4 durante la primera remoción. D: Vista de rasgo H7 durante la segunda remoción.

Burials analyzed in this work. A: North view of burial EA-1. B: North view of burial H6-1 during the first removal. C: South view of burial H4 during the first removal. D: View of burial H7 during the second removal. 
adultos, con la excepción del individuo H7-5, el cual, a pesar de haber sido asignado como subadulto, presentó un grado considerable de madurez y fusión epifisiaria. La razón de trabajar solamente con adultos se basa en que la metodología tafonómica utilizada solamente es aplicada para esta franja etaria, restringiendo por lo tanto las interpretaciones obtenidas a este grupo (Behrensmeyer 1978; Massigoge 2009; Massigoge et al. 2010).

La muestra total considerada para este trabajo comprende a 19 individuos, 17 adultos jóvenes (11 masculinos y seis femeninos), una mujer adulto mayor $\mathrm{y}$ un adolescente probablemente femenino de entre $13 \mathrm{y}$ 16 años al momento de la muerte. Para la determinación del sexo se tuvieron en cuenta la morfología de la pelvis y distintos indicadores del cráneo y la mandíbula (Acsádi y Nemeskéri 1970; Buikstra y Ubelaker 1994; Phenice 1969; Walker 2005; entre otros), así como los diámetros verticales de las cabezas femorales y humerales (Buikstra y Ubelaker 1994). Entre los criterios utilizados para la determinación de la edad se destacan la secuencia de erupción y formación dental (Ubelaker 1999). También fueron usados caracteres del os coxae, tales como indicadores de la superficie auricular (Buckberry y Chamberlain 2002; Lovejoy et al. 1985; Meindl y Lovejoy 1989) y de la sínfisis púbica (Brooks y Suchey 1990; Gilbert y McKern 1973; McKern y Stewart 1957; Todd 1921a, 1921b).

En total se analizaron 4.567 especímenes pertenecientes a 2.045 elementos. La representatividad total calculada (MAU\%, sensu Binford 1984; Lyman 1994) fue del $56 \%$, con la mayoría de las unidades esqueléticas con valores de MAU\% que superan el $80 \%$. Elementos tales como las rótulas derechas y los huesos de las manos y los pies se destacaron por su baja representatividad (16 y 30\%, respectivamente). El índice de fragmentación (IF) promedio (sensu Mondini 2003) para el total del conjunto fue igual a 0,45 , con cerca de la mitad del conjunto mostrando un IF superior a 0,8 (Bottini 2017).

En primer lugar, se comprobó la existencia de correspondencia anatómica entre elementos óseos para, por un lado, demostrar el carácter primario o secundario de los depósitos óseos y, por el otro, registrar el grado de desarticulación observado en y dentro de cada uno de los rasgos. Para ello se realizó el pareo o matching siguiendo las recomendaciones de Bökönyi (1970), Chaplin (1971), Todd y Frison (1992) y Barrientos (1997). También se llevaron a cabo el ensamblaje anatómico bilateral e intermembral en base a la propuesta de Todd y Frison (1992). Además, se revisaron las notas de campo y el registro fotográfico para observar y comprobar la existencia de correspondencia anatómica entre elementos óseos in situ. Los datos obtenidos se organizaron en una tabla, donde se presenta una clasificación abreviada de las articulaciones humanas y se establecen las relaciones articulares más frecuentes siguiendo la secuencia de desarticulación propuesta por Micozzi (1991) y Duday y Guillon (2006).

En segundo lugar, para comprobar la existencia de manipulación y desmembramiento de cadáveres, se realizó el análisis de marcas de corte, en base a las modificaciones provocadas en la superficie cortical por objetos cortantes (Binford 1981; Fisher 1995), y de las fracturas ocurridas en momentos perimortem, de acuerdo con los tipos de trauma descriptos por Lovell (1997). Las fracturas relevadas se clasificaron como huellas de corte asociadas a manipulación, perimortem, marcas postexhumación y, por último, se incluyó una clase para aquellas marcas (alteraciones mecánicas en la superficie cortical ósea) en las cuales no fue posible establecer un evidente origen antrópico (no identificadas). Los resultados porcentuales se presentan en relación al total de fracturas registradas. Cabe destacar que se clasificaron como perimortem solamente a aquellas fracturas que no presentaron señales de cicatrización ni evidencia clara de intencionalidad (Frayer 1997; Lovell 1997; Villa y Mahieu 1991; Walker 2001; White 1992; White y Toth 1989).

Por otro lado, también se determinó la presencia de actividad faunística. Carroñeros, roedores e insectos pueden provocar modificaciones que aportan valiosa información para la caracterización de las alteraciones post-depósito y la interpretación del comportamiento mortuorio (Binford 1981; Eickoff y Herrmann 1985; Horwitz y Smith 1988; Le Mort y Rabinovich 1994, 2002; entre otros). Entre los insectos, varias especies de coleópteros de la familia Dermestidae comúnmente colonizan cadáveres humanos. Por lo general éstos llegan al cuerpo cuando está en avanzado estado de descomposición, ya reducido a piel, cartílagos y huesos (Byrd y Castner 2009). Dentro de esta familia, el género Dermestes es el único que presenta larvas que agujerean sustratos sólidos para construir sus cámaras pupales (Peacock 1993). La mayor parte de los Dermestes son activos únicamente durante los meses cálidos (Byrd y Castner 2009) y sólo colonizan un cadáver cuando éste está expuesto (Huchet et al. 2011; Laudet y Antoine 2004; Martin y West 1995; entre otros). Por lo tanto, la evidencia de actividad de estos insectos puede aportar información acerca de laépoca de muerte de un individuo y de la exposición del cadáver a la intemperie. Para el análisis de la actividad de insectos se tuvo en cuenta la presencia de hoyos en la corteza ósea y la identificación de galerías de larvas en el tejido esponjoso (Huchet et al. 2013). Las galerías se identificaron a simple vista en aquellos casos en los cuales había quedado expuesto el hueso trabecular. Se midió, en los casos que fue posible, el diámetro de los hoyos con un calibre de Vernier $(0,02 \mathrm{~mm})$. Para el análisis de la acción de carnívoros y 
roedores se siguieron las propuestas de Binford (1981), Haglund et al. (1988) y Haglund (1992, 1997a y b), las cuales, basándose en evidencia forense, identifican el patrón de marcas provocada por animales (i.e., marcas de roído, perforaciones, hoyuelos, arrastres y surcos).

Finalmente, se registró la presencia/ausencia de pigmentos rojizos (ocre) y amarillos sobre la superficie de los distintos elementos analizados (Martínez et al. 2006). La presencia de pigmentos sobre restos óseos humanos ha sido registrada en varios sitios con entierros (Barrientos et al. 2002; González 2010; Martínez 2010; Martínez et al. 2006). Estos pigmentos son de variados colores, destacándose los rojos (hematita: Fe2O3), amarillos (óxido-hidróxido de hierro o goethita: $\mathrm{FeOOH}$ ), blancos (arcillas tales como la kaolinita y la illita), violáceos y rosados, siendo estos últimos los menos frecuentes (Mazzanti et al. 2014).

El registro de las variables tafonómicas se realizó macroscópicamente analizando la superficie cortical de los elementos óseos a través del examen a simple vista, lupas de mano (aumento 1,5 y 2,5X) y una lupa binocular estereoscópica (aumento hasta 50X), la cual fue utilizada en aquellos casos donde se requería visualizar las variables con un mayor nivel de detalle, principalmente en lo que respecta a las huellas de corte. Además se utilizaron datos de campo y fotografías. Se registraron separadamente los datos obtenidos por elemento según su lateralidad, salvo en el caso de las costillas, que fueron incluidas en un único apartado.

\section{Resultados}

La existencia de relación articular in situ se observó con mayor prevalencia en elementos de las extremidades inferiores, sobre todo de la articulación tibioperonea (Tabla 2). En cuanto a las extremidades superiores, la persistencia de la articulación del codo fue la mayormente registrada. Las articulaciones completamente ausentes fueron la articulación esternocostal y la cadera. En los rasgos $\mathrm{H} 4$ y H7 predominaron elementos articulados en individuos femeninos, mientras que en el H6-1, solo se observaron en masculinos. No se observóla existencia de diferencias en la lateralidad de los elementos articulados.

La presencia de alteraciones mecánicas en la superficie ósea se registró en el 2,84\% de la muestra. En cuanto a la presencia de fracturas perimortem y huellas de corte, éstas se registraron en el 2,20\% del total de elementos analizados, encontrándose en mandíbulas, vértebras cervicales, vértebras torácicas, sacros, omóplatos, clavículas, húmeros, cúbitos, coxales y fémures. En la Tabla 3 se puede observar que las fracturas perimortem se manifestaron con mayor frecuencia $(1,17 \%)$, seguidas por las huellas de corte $(1,03 \%)$, en menor medida marcas producidas
Tabla 2. Frecuencias de conexiones anatómicas observadas en los rasgos H4, H6-1 y H7.

Frequencies of anatomical connections observed in features H4, H6- 1 and H7.

\begin{tabular}{lcc}
\hline Articulación & Frecuencia & MNI* \\
\hline Tibioperonea & 6 & 4 \\
Codo & 4 & 3 \\
Sacroilíaca & 3 & 3 \\
Cráneo-Cervicales & 2 & 2 \\
Lumbares-Sacro & 2 & 2 \\
Huesos del pie & 2 & 1 \\
Témporomandibular & 1 & 1 \\
Acromioclavicular & 1 & 1 \\
Costotorácica & 1 & 1 \\
Radiocubital & 1 & 1 \\
Huesos de la mano & 1 & 1 \\
Vértebras lumbares & 1 & 1 \\
\hline
\end{tabular}

* MNI= número mínimo de individuos que mostraron la permanencia de la articulación

post-exhumación $(0,49 \%)$ y, por último, marcas no identificadas $(0,15 \%)$. Los marcadores antrópicos se registraron en mayor frecuencia en los individuos del rasgo $\mathrm{H}-4$ (74,63\% respecto del total de marcas), donde la mayoría fueron atribuidos a fracturas perimortem (40\% de marcas de origen antrópico del rasgo $\mathrm{H} 4$ ). Entre los cuatro rasgos analizados, los elementos afectados con mayor frecuencia fueron las costillas (43,1\% del total de elementos con marcas de origen antrópico) (Tabla 4). En el caso de los huesos largos, se registró la presencia de marcas de acción antrópica en el tercio distal de la diáfisis en húmeros y fémures, y en el tercio proximal de la diáfisis en cúbitos. En cuanto al sexo, se registró más evidencia de acción antrópica en elementos masculinos, especialmente relacionados con huellas de corte (Tabla 5 y Figura 3).

Con respecto a la presencia de actividad faunística, no se registraron indicadores de la acción de carroñeros o de roedores, tales como marcas de roído, perforaciones o surcos, en los elementos óseos y tampoco se observó, in situ, el desplazamiento de unidades dentro de cuevas o madrigueras. Sin embargo, alrededor de la mitad de los elementos analizados manifestaron la presencia de hoyos producidos por larvas de insectos. El rasgo más afectado fue el EA-1, el cual presentó hoyos en el $82,76 \%$ de los elementos afectados. ElrasgoH7 presentó el 42,42\% de los elementos afectados, mientras que los rasgos H6-1 y H4 presentaron el 35,06\% y el 33, $67 \%$, respectivamente. Los elementos que mayormente 
Tabla 3. Distribución y prevalencias de tipos de marcas registradas por elementos en los entierros. Distribution and prevalence of types of marks by elements in the burials.

\begin{tabular}{|c|c|c|c|c|c|c|c|c|c|c|}
\hline & \multicolumn{2}{|c|}{$\mathrm{EA}-1(\mathrm{NME}=138)$} & \multicolumn{2}{|c|}{$\mathrm{H} 4(\mathrm{NME}=762)$} & \multicolumn{2}{|c|}{ H6-1 (NME=636) } & \multicolumn{2}{|c|}{ H7 (NME=509) } & \multicolumn{2}{|c|}{ Total $(\mathrm{NME}=2045)$} \\
\hline & $\mathrm{N}$ & $\%$ & $\mathrm{~N}$ & $\%$ & $\mathrm{~N}$ & $\%$ & $\mathrm{~N}$ & $\%$ & $\mathrm{~N}$ & $\%$ \\
\hline Fracturas peri-mortem & - & - & 20 & 2,62 & 4 & 0,63 & - & - & 24 & 1,17 \\
\hline Huellas de corte & - & - & 10 & 1,31 & 3 & 0,47 & 8 & 1,57 & 21 & 1,03 \\
\hline Marcas post-exhumación & - & - & 10 & 1,31 & - & - & - & - & 10 & 0,49 \\
\hline No identificadas & - & - & 3 & 0,39 & - & - & - & - & 3 & 0,15 \\
\hline Total & - & - & 43 & 5,64 & 7 & 1,10 & 8 & 1,57 & 58 & 2,84 \\
\hline
\end{tabular}

$\mathrm{N}=$ Número de elementos afectados.

Tabla 4. Prevalencias por elementos de la presencia de las alteraciones mecánicas óseas relevadas en relación al total de elementos afectados $(\mathrm{N}=58)$.

Prevalences by elements of the presence of the mechanical bone alterations registered in relation to the total of affected elements.

\begin{tabular}{|c|c|c|c|c|c|c|c|c|c|c|}
\hline \multirow[t]{2}{*}{ Elementos } & \multicolumn{2}{|c|}{ Fracturas peri-mortem } & \multicolumn{2}{|c|}{ Huellas de corte } & \multicolumn{2}{|c|}{$\begin{array}{l}\text { Marcas post } \\
\text { exhumación }\end{array}$} & \multicolumn{2}{|c|}{ No identificadas } & \multicolumn{2}{|c|}{ Total } \\
\hline & MNE & $\%$ & MNE & $\%$ & MNE & $\%$ & MNE & $\%$ & MNE & $\%$ \\
\hline Cráneo & 7 & 12,07 & - & - & - & - & - & - & 7 & 12,07 \\
\hline Mandíbulas & - & - & 2 & 3,45 & 1 & 1,72 & - & - & 3 & 5,17 \\
\hline V. Cervicales & - & - & 2 & 3,45 & - & - & - & - & 2 & 3,45 \\
\hline V. Torácicas & - & - & 2 & 3,45 & - & - & - & - & 2 & 3,45 \\
\hline Sacros & - & - & 1 & 1,72 & - & - & - & - & 1 & 1,72 \\
\hline Costillas & 16 & 27,59 & 5 & 8,62 & 4 & 6,90 & - & - & 25 & 43,10 \\
\hline Omóplatos & - & - & 3 & 5,17 & - & - & - & - & 3 & 5,17 \\
\hline Clavículas & - & - & 1 & 1,72 & 1 & 1,72 & 1 & 1,72 & 3 & 5,17 \\
\hline Húmeros & - & - & 1 & 1,72 & - & - & 1 & 1,72 & 2 & 3,45 \\
\hline Radios & - & - & - & - & 1 & 1,72 & - & - & 1 & 1,72 \\
\hline Cúbitos & 1 & 1,72 & 1 & 1,72 & - & - & - & - & 2 & 3,45 \\
\hline Coxales & - & - & 1 & 1,72 & 1 & 1,72 & - & - & 2 & 3,45 \\
\hline Fémures & - & - & 2 & 3,45 & 1 & 1,72 & - & - & 3 & 5,17 \\
\hline Tibias & - & - & - & - & 1 & 1,72 & 1 & 1,72 & 2 & 3,45 \\
\hline Total & 24 & 41,38 & 21 & 36,21 & 10 & 17,24 & 3 & 5,17 & 58 & 100,00 \\
\hline
\end{tabular}

Tabla 5. Distribución y prevalencia de tipos de marcas registradas según el sexo en relación al total de elementos afectados $(\mathrm{N}=58)$.

Distribution and prevalence of types of marks observed according to sex in relation to the total of affected elements.

\begin{tabular}{lcccccccccc}
\hline & \multicolumn{2}{c}{ Fracturas perimortem } & \multicolumn{2}{c}{ Huellas de corte } & \multicolumn{2}{c}{ Marcas post exhumación } & \multicolumn{2}{c}{ No identificadas } & \multicolumn{2}{c}{ Total } \\
& MNE & $\%$ & MNE & $\%$ & MNE & $\%$ & MNE & $\%$ & MNE & $\%$ \\
\hline Femeninos & 11 & 18,97 & 7 & 12,07 & 4 & 6,90 & 3 & 5,17 & 25 & 43,10 \\
Masculinos & 9 & 15,52 & 14 & 24,14 & 6 & 10,34 & - & - & 29 & 50,00 \\
H6-1-1 Cost & 4 & 6,90 & - & - & - & - & - & - & 4 & 6,90 \\
Total & 24 & 41,38 & 21 & 36,21 & 10 & 17,24 & 3 & 5,17 & 58 & 100,00 \\
\hline
\end{tabular}




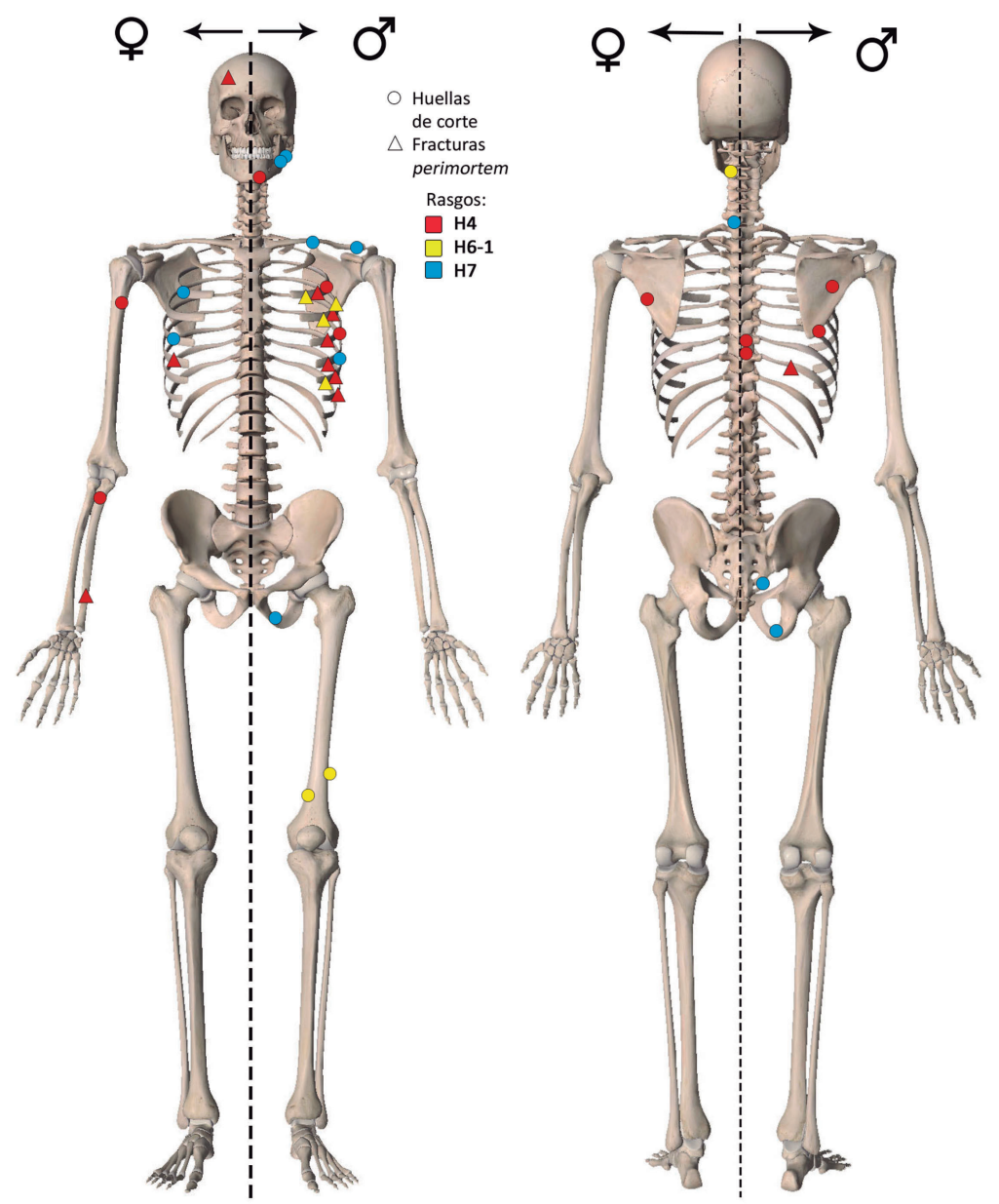

Figura 3. Distribución de alteraciones de origen antrópico en vistas anterior y posterior del esqueleto. Las fracturas perimortem en costillas pertenecientes al rasgo H6-1 se han colocado arbitrariamente del lado masculino del esqueleto.

Distribution of anthropic marks in anterior and posterior views of the skeleton. Perimortem fractures in the ribs from feature H6-1 have been arbitrarily placed on the masculine side of the skeleton.

evidenciaron la actividad de insectos fueron vértebras torácicas, costillas, coxales, fémures y huesos de los pies (más del 60\%). Los huesos menos frecuentemente afectados fueron los esternones $(25 \%)$. El diámetro de los hoyos varió entre 2,1 y $6,8 \pm 0,02 \mathrm{~mm}$, siendo la moda de 3,64 $\pm 0,02 \mathrm{~mm}$ (promedio $=3,7 \pm 0,02$ $\mathrm{mm}$ ). Los sitios donde se observó una mayor frecuencia de hoyos fueron los cuerpos vertebrales y las epífisis de los huesos largos (Figura 4.A).

Finalmente, en las Tablas 6,7 y 8 se pueden observar las prevalencias de elementos y unidades muestrales afectados por la presencia de pigmentos rojizos o amarillos. Sólo el 13,42\% del total de las unidades muestrales manifestó la presencia de pigmentos rojos, posiblemente ocre, con una distribución en forma de pequeñas manchas rojas escasas e irregulares (Figura 4.B). La mayor frecuencia de elementos pigmentados se observó en el rasgo $\mathrm{H} 4$, con cerca del $16 \%$ de elementos afectados, mientras que el valor más bajo fue el del rasgo H6-1, con aproximadamente el 9\% de las unidades muestrales afectadas (Tabla 6 y 7). El EA-1 presentó una llamativa intensidad en el teñido del cráneo y el sedimento circundante. En el rasgo $\mathrm{H} 7$ los elementos más frecuentemente pigmentados fueron costillas, húmeros y fémures, mientras que en $\mathrm{H} 4$ lo fueron los cráneos, vértebras torácicas, costillas, cúbito, fémures y tibias. También se observó la presencia de un depósito de color amarillo en el 3,2\% de las unidades muestrales, de los cuales el $88 \%$ corresponde al rasgo H4 (Tablas 6 y 8, Figura 4.C). 


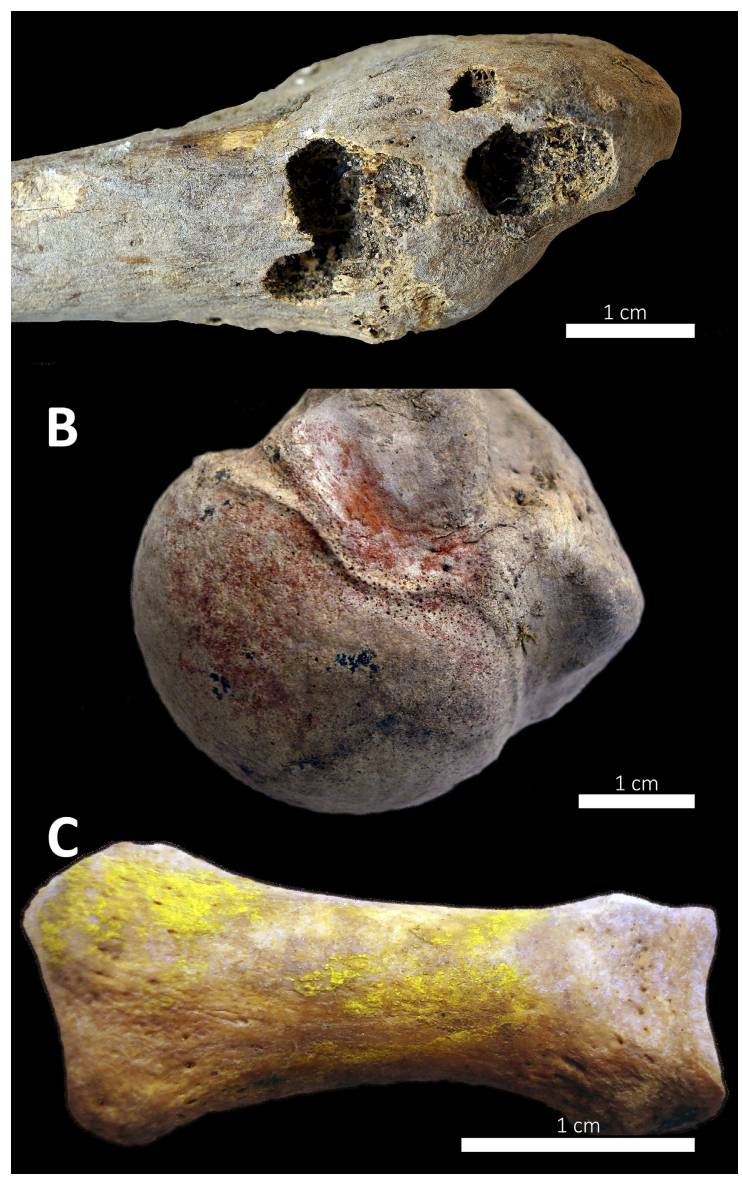

Figura 4. H4-2: A. Epífisis distal de peroné derecho mostrando numerosos hoyos de insectos. B. Epífisis proximal de húmero derecho mostrando manchas de pigmento ocre. C. Primera falange de pulgar de mano derecha exhibiendo manchas amarillas.

H4-2: A. Distal epiphysis of right fibula showing numerous holes of insects. B. Proximal epiphysis of right humerus showing ocher pigment spots. C. First phalanx of thumb of right hand exhibiting yellow spots.

Tabla 6. Prevalencia de elementos afectados por la presencia de pigmentos rojizos y amarillos por rasgo.

Prevalence of elements affected by the presence of reddish and yellow pigments by feature.

\begin{tabular}{ccc}
\hline Rasgos & Ocre $\%$ & Manchas Amarillas \% \\
\hline EA & 13,79 & - \\
H7 & 9,85 & 1,52 \\
H4 & 20,10 & 7,54 \\
H6-1 & 7,79 & - \\
\hline
\end{tabular}

Tabla 7. Distribución porcentual de pigmento ocre en unidades muestrales.

Percent distribution of ocher pigment in sampling units.

\begin{tabular}{|c|c|c|c|}
\hline $\begin{array}{l}\text { Unidades } \\
\text { Muestrales }\end{array}$ & Ocre $\%$ & $\begin{array}{l}\text { Unidades } \\
\text { Muestrales }\end{array}$ & Ocre $\%$ \\
\hline Cráneos & 38,89 & Radios Izq. & 5,88 \\
\hline Mandíbulas & 13,33 & Radios Der. & 0,00 \\
\hline V. Cervicales & 0,00 & Manos Izq. & 7,14 \\
\hline V. Torácicas & 11,11 & Manos Der. & 7,14 \\
\hline V. Lumbares & 5,56 & Coxales Izq. & 0,00 \\
\hline Sacros & 5,88 & Coxales Der. & 17,65 \\
\hline Costillas & 36,67 & Fémures Izq. & 16,67 \\
\hline Esternones & 8,33 & Fémures Der & 23,53 \\
\hline $\begin{array}{l}\text { Omóplatos } \\
\text { Izq. }\end{array}$ & 0,00 & Tibias Der & 11,11 \\
\hline $\begin{array}{l}\text { Omóplatos } \\
\text { Der. }\end{array}$ & 17,65 & Tibias Izq. & 5,88 \\
\hline $\begin{array}{l}\text { Clavículas } \\
\text { Izq. }\end{array}$ & 0,00 & Peronés Izq. & 5,26 \\
\hline $\begin{array}{l}\text { Clavículas } \\
\text { Der. }\end{array}$ & 12,50 & Peronés Der & 5,56 \\
\hline Húmeros Izq. & 16,67 & Rótulas Izq. & 0,00 \\
\hline Húmeros Der. & 23,53 & Rótulas Der & 33,33 \\
\hline Cúbitos Izq. & 6,25 & Pies Izq. & 11,76 \\
\hline Cúbitos Der. & 17,65 & Pies Der & 6,67 \\
\hline
\end{tabular}

Tabla 8. Distribución porcentual de manchas amarillas en unidades muestrales.

Percent distribution of yellow pigments in sampling units.

\begin{tabular}{lc}
\hline Unidades Muestrales & $\begin{array}{c}\text { Manchas } \\
\text { Amarillas } \%\end{array}$ \\
\hline V. Cervicales & 0,19 \\
V. Torácicas & 0,19 \\
Sacros & 0,19 \\
Costillas & 0,19 \\
Esternones & 0,19 \\
Omóplatos Izq. & 0,19 \\
Omóplatos Der. & 0,19 \\
Manos Der & 0,38 \\
Fémures Izq. & 0,38 \\
Fémures Der & 0,19 \\
Peronés Izq. & 0,19 \\
Peronés Der. & 0,19 \\
Pies Izq. & 0,38 \\
Pies Der. & 0,19 \\
\hline &
\end{tabular}




\section{Discusión}

El EA-1 habría sido el único entierro primario del sitio. A partir del análisis de las notas de campo y del registro fotográfico se pudo comprobar la existencia de conexión entre los huesos que formaban las articulaciones lábiles (i.e., cráneo y mandíbula, posición de las costillas con respecto a la columna vertebral, de los tarsos, metatarsos, carpos, metacarpos y sus falanges, entre otros) (Duday y Guillon 2006), lo cual sugiere que el cuerpo habría sido enterrado cuando aún se encontraba con total relación anatómica. Con respecto a los demás rasgos, la presencia de huesos articulados revela que estas articulaciones habrían resistido varias etapas y procesos: el depósito primario, una exhumación, el/los proceso/s de descarne y desarticulación, el armado de paquetes, el traslado hacia el entierro final, la inhumación en la sepultura definitiva y, finalmente, los procesos post-depósito (meteorización, actividad radicular, deterioro químico, etc.). Es probable que otros dos factores favorecieran al mantenimiento de las relaciones articulares. Por un lado, la naturaleza friable del sedimento, el cual fue ocupando los espacios intersticiales existentes entre los huesos, habría permitido mantener dichas relaciones (Duday y Guillon 2006) y, por el otro, la presencia inicial de algún tipo de envoltorio que contuvo los elementos y los mantuvo relativamente en la posición original en la cual habían sido posicionados dentro del paquete funerario. Es importante destacar que comprobar la existencia de huesos largos articulados resultó un poco controvertido porque se observó que, en general, los conjuntos esqueléticos presentaban los huesos de las extremidades superiores e inferiores acomodados de manera paralela y adyacente unos con otros. Esta situación tornó dificultosa la tarea de establecer si realmente se había mantenido la relación articular correspondiente porque los huesos largos habían sido ingresados manteniendo algunas conexiones (debido a la persistencia de algunas estructuras articulares) o si la asociación era solamente el resultado del acomodamiento intencional de los huesos largos. Además, también fue determinante la posición que habría ocupado cada paquete dentro de los rasgos, ya que los paquetes ubicados a mayor profundidad fueron los que mayormente manifestaron la presencia de elementos en relación articular.

De acuerdo con la secuencia de desarticulación propuesta por Micozzi (1991) para vertebrados, la permanencia de las articulaciones atlantooccipital, temporomandibular y de las vértebras cervicales sugiere la desarticulación parcial de individuos cuya muerte ha sido relativamente reciente. Se hallaron indicios de permanencia de estas articulaciones en los rasgos H7 y H6-1. También es destacable que el individuo H7-1 presentó las siguientes partes articuladas: cráneo y vértebras cervicales, vértebras torácicas, costillas, omóplatos y clavículas, vértebras lumbares, sacro y coxales, mano derecha y tibia y peroné. Duday y Guillon (2006) clasifican a las articulaciones de las manos como lábiles y, de este modo, su presencia sería un claro indicio de manipulación en momentos recientes a su muerte. Además, el grado de desarticulación con el que fueron inhumados los distintos individuos que conformaban cada uno de los rasgos no habría sido el mismo, lo cual sugiere que no todos los difuntos sufrían exactamente el mismo tratamiento para el armado de paquetes funerarios.

Todos los entierros múltiples manifestaron la presencia de alteraciones mecánicas de origen antrópico. Las más frecuentemente observadas fueron las fracturas perimortem y las huellas de corte. A pesar de la asignación efectuada en base a la metodología propuesta por Binford (1981), no fue posible distinguir, en algunos casos, si las marcas correspondían al conjunto de procedimientos que constituían las prácticas mortuorias particulares de este grupo de cazadoresrecolectores o si efectivamente fueron producto de situaciones de violencia interpersonal.

Las huellas de corte asignadas a la manipulación de los cadáveres fueron mayormente registradas en costillas, escápulas, mandíbulas, vértebras (cervicales y torácicas) y fémures, representando un total de 21 elementos de la muestra. Las fracturas perimortem se registraron en costillas, cráneos y un cúbito, y en ninguno de estos elementos se observaron signos de cicatrización. En costillas, las cuales representan la gran mayoría de los elementos que manifestaron fracturas perimortem, las mismas se registraron en el tercio proximal de las diáfisis, en algunos casos en la región cercana al ángulo y, en otros, más cercanos a la región del cuello, y habrían sido más comunes en masculinos que en femeninos ( $\mathrm{NME}=13$ y $\mathrm{NME}=3$, respectivamente). La mayoría de las fracturas registradas fueron del tipo oblicuas, aunque se observaron algunas en espiral (Figura 5). Todas corresponderían a costillas ubicadas entre la quinta y décima, las cuales, según Brickley (2006), son las más comúnmente afectadas por fracturas. Si bien es arriesgado proponer una causa directa como la responsable de las fracturas costales relevadas, como la mayoría de los individuos que mostraron costillas fracturadas también presentaron inclusiones líticas en otros elementos óseos, sería válido proponer que tales fracturas se hayan producido durante el desarrollo de ataques violentos. Sin embargo, es probable que algunas (si no la mayoría) de dichas fracturas hayan sido provocadas durante el tratamiento de los cadáveres para el armado de los paquetes funerarios.

Un cúbito derecho, perteneciente al individuo femenino H4-3, presentó una fractura oblicua en el tercio distal de la diáfisis (Figura 6.A). Las fracturas 


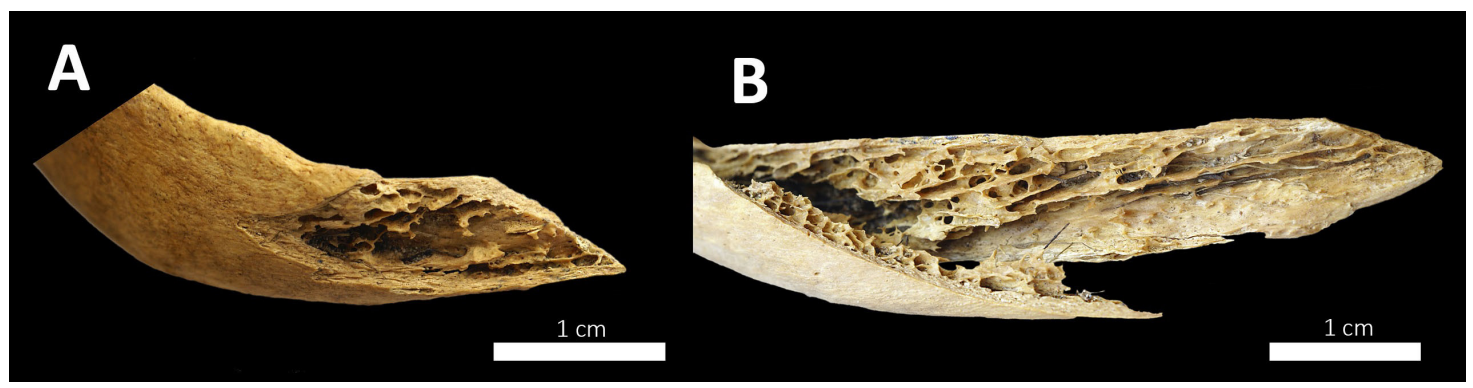

Figura 5. Fracturas perimortem en costillas registradas en H4-6 (A) y H4-7 (B).

Perimortem fractures in ribs from individuals H4-6 (A) and H4-7 (B).

de cúbito no son comunes y generalmente se presentan como fracturas transversales en el olécranon o en el tercio proximal de la diáfisis (Lovell 1997). Sin embargo, es importante destacar que este mismo cúbito, además de no manifestar ningún signo de cicatrización, presentó una marca de corte en el aspecto medial de la epífisis proximal (Figura 6.B), por lo que sería probable que esta fractura haya sido provocada durante la manipulación del cadáver.

En cuanto a las huellas de corte, éstas poseen las características típicas de herramientas líticas (Lyman 1994). Se presentaron generalmente como marcas cortas, tanto aisladas como en grupos. Algunas huellas eran profundas, como la que presentó el cúbito derecho del individuo H4-3 (Figura 6.B), mientras que otras eran muy superficiales, como las de la clavícula derecha del individuo H7-4 (Figuras 6.C y 6.D). En cuanto a su localización, fueron registradas, en algunos casos, en el sitio de inserción de músculos, tendones y ligamentos (representando el 66,7\%), mientras que, en otros, la localización no mostró ningún patrón evidente. La frecuencia de huellas de corte fue relativamente baja, con una prevalencia general del 1,03\% de los elementos analizados. Sin embargo, es probable que la alteración de la corteza ósea debido a agentes y procesos postdepósito (tales como meteorización, deterioro químico, grabado radicular, entre otros) haya obliterado parcial o completamente algunas marcas antrópicas, sobre todo las huellas de manipulación. Por su parte, González (2010), en su estudio realizado sobre entierros secundarios del sitio Paso Alsina 1, registró porcentajes de marcas de corte más elevados: $4 \%$ para el entierro 2, 14 y $22 \%$ para los entierros 10 A y B, respectivamente. Posteriormente, en González (2013) se presentan datos sobre el entierro $8(6,7 \%)$ y se informa un porcentaje superior para el entierro $2(9,3 \%)$.

Al analizar las huellas de corte que serían una consecuencia de los procedimientos llevados a cabo para la desarticulación de los cadáveres, se observó la existenciade casos en los cuales las marcas se presentaron en articulaciones lábiles (mandíbula y coxal derecho en individuo H7-3, cúbito derecho en $\mathrm{H} 4-3$ y vértebra $\mathrm{C} 3$ en H6-1-6) (Figuras 6.B, 7.A y 7.B). La presencia de huellas de corte sobre la inserción del músculo masetero y en el lado anterior de la rama mandibular ha sido ampliamente reconocido en la literatura, en la cual se las asocia tanto a prácticas mortuorias como a canibalismo (Stodder 2008; White 1992). Además, se registraron huellas de corte en el aspecto ventral de una costilla del individuo H7-3 (Figura 7.C), que evidenciaría ser producto de prácticas de evisceración (Binford 1981). Por otro lado, la presencia de huellas en los procesos espinosos de las vértebras sería, según Binford (1981), un claro indicador de descarne (Figura 7.D). Estos resultados sugieren que el tiempo transcurrido entre el momento de la muerte y la acción de desarticulación no necesariamente habría sido lo suficientemente largo como para permitir la desarticulación natural del cadáver. Además, la presencia de estas huellas apoya aún más la hipótesis de que el intervalo entre el momento de la muerte y la manipulación del cadáver no habría sido el mismo para todos los inhumados en los entierros múltiples.

A partir de los restos analizados en este trabajo no se pudo comprobar la existencia de un patrón sistematizado en el proceso de desarticulación. Si bien es cierto que costillas y omóplatos fueron los huesos que más frecuentemente desplegaron huellas de corte, tales huellas presentaron siempre características muy diferentes, aun cuando se trataba del mismo elemento, ya que cambiaban de tamaño, posición, orientación y profundidad. Se observó que los individuos masculinos presentaron el doble de huellas de manipulación que los femeninos, el cual sería un resultado esperable ya que los hombres poseen generalmente una mayor masa muscular, con inserciones musculares más desarrolladas y, por lo tanto, más difíciles de remover. Es llamativo el hecho de que, aun cuando casi la totalidad de los entierros analizados son del tipo secundario, se hayan registrado relativamente bajas prevalencias de huellas de 


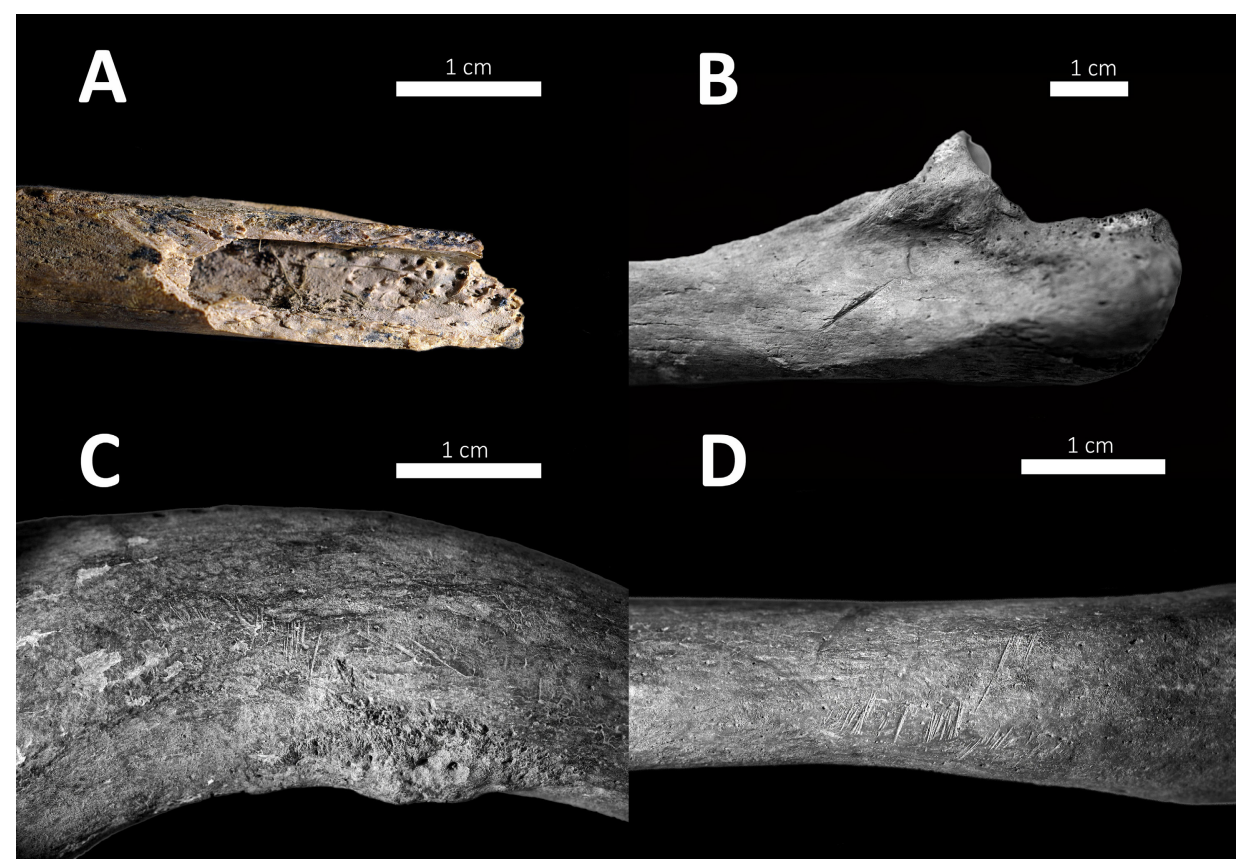

Figura 6. A y B: cúbito derecho de H4-3. A: fractura perimortem en el tercio distal de la diáfisis. B: Huella de corte en epífisis proximal. C y D: clavícula derecha de H7-4 mostrando huellas de corte. C: vista superior del extremo acromial. D: vista anterior de la diáfisis media.

A and B: right ulna of individual H4-3. A: Perimortem fracture in the distal third of the diaphysis. B: Cutting mark on the proximal epiphysis. $C$ and D: right clavicle of individual H7-4 showing manipulation marks. $C$ : top view of the acromial end. D: anterior view of the middle diaphysis.

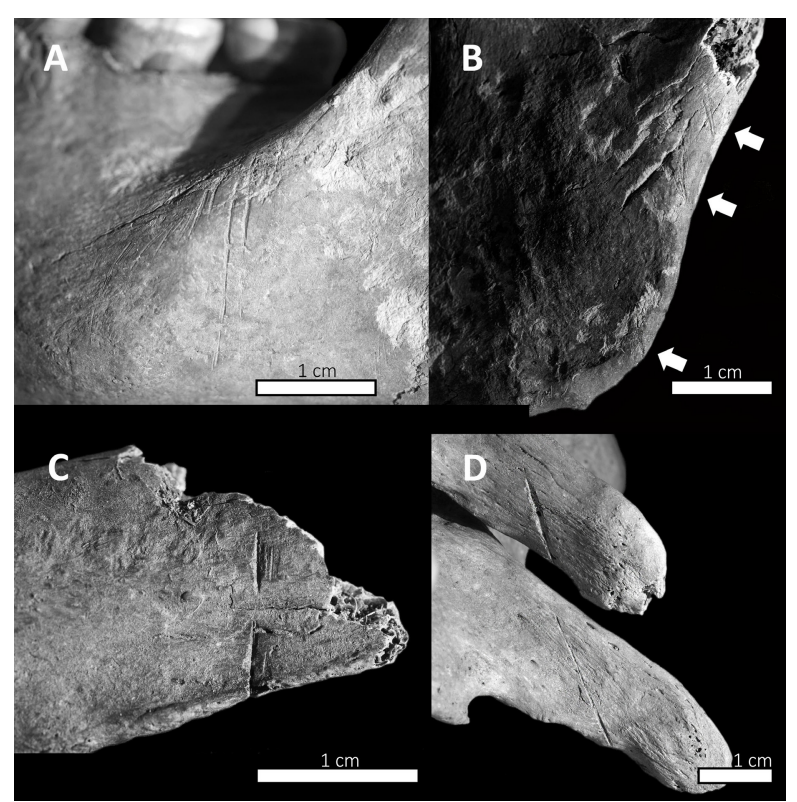

Figura 7. A, B y C: H7-3. A: Vista lateral izquierda de mandíbula con huellas de corte sobre línea oblicua. B: Huellas de corte sobre borde posterior de rama mandibular (flechas blancas). C: Aspecto interno de cuerpo de costilla izquierda con huellas de corte. D: H4-6: vista lateral izquierda de dos vértebras torácicas subsiguientes, mostrando huellas de corte en sus procesos espinosos.

A, B, and C: Individual H7-3. A: Left side view of jaw with cut marks on oblique line. B: Cut-marks on the posterior edge of the mandibular ramus (white arrows). C: Internal appearance of left rib body with cut marks. D: Individual H4-6: left lateral view of two subsequent thoracic vertebrae, showing cut marks in their spinous processes. 
corte. Esto podría explicarse en parte por la experiencia y la habilidad de la persona encargada de llevar a cabo la manipulación, ya que, probablemente, aquellos más experimentados causaban un menor número de huellas que los inexpertos (Dewbury y Russell 2007). Bello y colegas (2016) plantean, por un lado, que en entierros secundarios donde la manipulación se llevó a cabo en cadáveres en avanzado estado de descomposición, es lógico pensar que las huellas sean menos frecuentes, sobre todo en articulaciones lábiles, porque los cuerpos estarían ya naturalmente desarticulados. Por otro lado, estos autores plantean que un estado más deshidratado del cadáver exigiría un mayor esfuerzo para el descarne y causaría, por consiguiente, cortes más profundos (Bello et al. 2016). Por lo tanto, lo anteriormente expuesto sugiere que los individuos de los rasgos H4, H6-1 y H7 habrían sido manipulados en diferentes tiempos luego de la muerte y/o que las personas encargadas de la desarticulación poseían destrezas muy distintas.

Aproximadamente el $40 \%$ de los elementos analizados presentó hoyos producidos por larvas de insectos. Se observó una aparente preferencia de las larvas hacia los cuerpos vertebrales y las epífisis de huesos largos. La colonización habría sido circunstancial y respondería a la invasión de aquellos elementos que se presentan en mayor número (tales como costillas y vértebras) y con mayor superficie disponible (p.ej., coxales). Además, es probable que la supuesta predilección por las epífisis de huesos largos, entre otros, responda a la búsqueda de tejido blando seco (i.e., músculos, tejidos y ligamentos) en donde las larvas pudieran establecer sus cámaras pupales (Martin y West 1995). El diámetro promedio de los hoyos fue de $3,7 \pm 0,02 \mathrm{~mm}$, con un rango variable entre 2,1 y 6,8 $\pm 0,02 \mathrm{~mm}$. Estos valores son relativamente próximos a aquellos registrados por Huchet et al. (2013) en restos humanos de la Edad del Bronce Medio en Medio Oriente (rango de cámaras cilíndricas: 2,1 a 2,9 mm y cámaras cónicas: 2,3 y 5,6 mm). Aunque no se halló ningún resto duro del organismo que habría generado las cavidades, algunos investigadores proponen a Dermestes peruvianus como responsable de marcas similares registradas en restos óseos humanos en los sitios Chenque I, en la provincia de La Pampa (Di Donato 2007), y en el sitio Alero Mazquiarán, provincia de Chubut (Fugassa et al. 2008). Sin embargo, dado que la mayoría de las especies del género Dermestes comparten un tamaño similar, los hoyos excavados por las distintas larvas no diferirían notoriamente en sus dimensiones (Hinton 1945).

El rasgo que presentó mayor prevalencia de hoyos de insectos fue el EA-1, con más del 80\% de los huesos afectados. Esto sugiere que este individuo habría fallecido durante la temporada estival y que al menos su cadáver habría permanecido expuesto a la intemperie un tiempo relativamente prolongado. Pero esta elevada frecuencia de hoyos indica, ante todo, que el cadáver sostuvo una población numerosa de derméstidos, la cual se vio de pronto sometida a una gran competencia por falta de alimentos y sitios apropiados para la formación de las cámaras pupales, por lo que debieron recurrir al tejido óseo. Esta situación respondería a que el EA-1, a diferencia de los demás rasgos, es un entierro primario que al momento de la inhumación probablemente mantenía todavía suficiente tejido blando como para sostener a dicha población. El entierro del cadáver habría mantenido aislada a la población, lo que desencadenaría una posterior situación de competencia intraespecífica por la necesidad de crear puparios protegidos mediante la horadación de los huesos. Los datos relevados durante el trabajo de campo indican que el individuo EA-1 terminó de esqueletizarse estando enterrado. Esto plantea la probabilidad de que la invasión de los derméstidos se habría producido antes del entierro y que, en ese momento, el cadáver habría aún mantenido las conexiones anatómicas lábiles, tales como las articulaciones témporomandibular, de los huesos de las manos y de los pies (Duday y Guillon 2006). Si bien no se considera una condición esencial, el cadáver debió estar lo suficientemente deshidratado como para poder ser colonizado por los derméstidos. Esto es congruente con el ambiente árido del sur de La Pampa, sobre todo durante la época estival.

En el caso de los demás rasgos, los cuales se trataban de entierros múltiples donde habría existido una desarticulación intencional de los cadáveres, deben considerarse dos cuestiones. Primero, no se ha podido determinar si los huesos ya estaban horadados al momento de ser inhumados o si esto sucedió en momentos post entierro. Si antes de ser desarticulados los cadáveres eran expuestos al ambiente para acelerar su descomposición, la colonización podría haber ocurrido en esa etapa. La segunda cuestión se refiere a la cantidad de tejido blando que mantenían los cuerpos al momento del entierro. Aunque la presencia de algunas partes articuladas en el depósito final respaldaría el hecho de que los huesos no estaban completamente desprovistos de tejido blando, no ha sido posible precisar el tiempo transcurrido entre el deceso de los individuos y su inhumación final.

En base a lo expuesto más arriba, podrían proponerse varias hipótesis. Por un lado, los cadáveres podrían haber sufrido la invasión de insectos durante el proceso de descomposición, antes de que fuesen desarticulados. Por el otro, si se supone que los derméstidos colonizaron los restos luego del proceso de desarticulación y descarne, tendríamos dos hipótesis principales: (1) los restos habrían sido colonizados antes de ser enterrados o (2) los restos sufrieron una invasión por parte de poblaciones preexistentes en el rasgo, las cuales habrían ingresado 
en entierros anteriores (Huchet et al. 2013). Esta última hipótesis sería factible únicamente si los rasgos múltiples estuviesen conformados por más de un evento de inhumación (i.e., si se tratara de tumbas colectivas). Es llamativo el hecho de que todos los rasgos que contenían entierros múltiples tengan, aproximadamente, el mismo porcentaje de elementos afectados (aunque distribuidos de manera diferencial). Si partimos de la hipótesis de un uso recurrente y diacrónico de los rasgos como estructuras funerarias, podría proponerse que uno o más de los paquetes habrían contenido insectos al momento de la inhumación (dependiendo de la época de muerte) y que éstos después invadieran a los paquetes que no habían estado inicialmente infestados. Por otro lado, también podría tratarse de un único evento de entierro (sincrónico), el cual habría sucedido en época estival y habría permitido la infestación de insectos en los paquetes funerarios. A favor de la sincronía entre los rasgos múltiples podemos mencionar los resultados de los fechados radiocarbónicos efectuados que dieron valores con un alto grado de homogeneidad. También existiría la posibilidad de que se trate de un único evento de entierro que se produjo en alguna época distinta a la estival, pero que algunos de los paquetes funerarios hubieran sido confeccionados en momentos estivales, estando de este modo invadido por insectos. Como destacan algunos autores, la sincronía de la inhumación final en entierros secundarios no implica necesariamente la sincronía en la muerte de los inhumados (Masset 1993; Roksandic 2002; Ubelaker 1974, 1981). En este caso, los individuos inhumados ingresarían en un evento determinado sin importar el tiempo pasado desde el momento de la muerte, lo cual se reflejaría en falta de uniformidad en el estado de descomposición de los cadáveres (Metcalf y Huntington 1991). Otros factores que estarían a favor de la sincronía interna de cada uno de los rasgos incluyen a los que dan cuenta del carácter único de los mismos. Por citar algunos ejemplos, el rasgo $\mathrm{H} 7$ no presentó fracturas perimortem ni inclusiones líticas entre sus elementos y el rasgo H6-1 contenía, de los seis individuos adultos, sólo un femenino.

Otro aspecto importante para destacar es la forma de armado de los paquetes funerarios, los cuales estaban conformados por huesos total o parcialmente desarticulados contenidos en envoltorios. Se supone que estos envoltorios se confeccionaban con cuero, principalmente de guanaco (Lama guanicoe) y, según Berón y colaboradores (2012), de piel de ñandú o choique (Rhea sp.). Es probable entonces que estas envolturas sirvieran de cebo y alimento a estos insectos asegurando, de este modo, su colonización.

Por su parte, la presencia de pigmentos sugiere que la tinción intencional de los huesos parece haber ocurrido durante la formación de los paquetes, pero la baja frecuencia y distribución aislada de las manchas no permiten inferir el modo en que fueron coloreados.
El análisis químico de estos pigmentos probablemente pueda revelar más información sobre la preparación y procedencia de estos. El uso de tintes rojizos en rituales mortuorios ha sido común a lo largo de todo el continente y ha sido mayormente asociado con las prácticas de desmembramiento y descarne (Latcham 1915). En Argentina, la presencia de pigmentos sobre restos óseos humanos ha sido registrado en varios sitios de entierros (Barrientos et al. 2002; González 2010; Martínez 2010; Martínez et al. 2006). En la región pampeana, la utilización de ocre en entierros ya ha sido documentada anteriormente en los sitios La Petrona 2 (Martínez y Figuerero Torres 2000) y Paso Alsina 1 (Martínez et al. 2006, 2012), ambos localizados en cercanías del río Colorado, en el sur de la provincia de Buenos Aires. De este modo, la presencia de manchas de ocre en los huesos analizados parece estar directamente vinculada con costumbres funerarias ampliamente difundidas entre los antiguos pobladores de Pampa y Patagonia.

En un intento de reconstruir los eventos que acontecieron sobre los restos óseos humanos del sitio MP, a partir de los datos recolectados y de su interpretación, queremos destacar las siguientes consideraciones. En primer lugar, queda claramente de manifiesto la complejidad de los ritos que se llevaban a cabo durante los entierros secundarios, los cuales se tornaban aún más complejos cuando se realizaba la inhumación de numerosos fallecidos. Esta forma de entierro, que implica la realización de un depósito primario y, posteriormente, la construcción de la tumba definitiva (o depósito secundario), con la reducción y empaquetamientos de los restos humanos entre medio, ha sido observada en otros hallazgos arqueológicos, tanto en la provincia de $\mathrm{La}$ Pampa, como en el sur de la provincia de Buenos Aires y el norte de la Patagonia (Barrientos 1997; Barrientos y Leipus 1997; Barrientos et al. 2002; Flensborg et al. 2017; Mariano 2011; Martínez y Figuerero Torres 2000; Martínez et al. 2012; Mazzia et al. 2004; Scabuzzo y Politis 2006; ). Dentro de este cuadro resulta llamativo el hecho de que exista un entierro primario simple, el cual, sin duda, también es de naturaleza claramente intencional (recuérdese la disposición del cuerpo y la presencia de ocre). Es probable que la respuesta a esta modalidad de inhumación "excepcional" sea mucho más simple de lo esperado, por ejemplo, que el individuo haya muerto en un lugar cercano al sitio de entierro. Sin embargo, la presencia de ocre y la alta frecuencia de hoyos de insectos sugieren que este individuo se encontraba en un estado avanzado de descomposición al momento del entierro. En las regiones pampeana y norpatagónica se han registrado entierros primarios ya desde finales del Holoceno Temprano (aprox. 8000 años AP) (Politis et al. 2014). Por lo general se presentan con una disposición similar al EA-1 de MP, posición decúbito lateral, derecho o izquierdo, con mayor o menor flexión de miembros inferiores, acompañados por ajuar funerario y con 
presencia de pigmentos (Cúneo et al. 2016; Martínez et al 2012; Politis et al. 2014).

En cuanto a las fuentes etnográficas que describen las costumbres funerarias de las poblaciones de cazadores-recolectores en primeros momentos de la conquista, sobre todo en la región norpatagónica, Latcham (1915) se refiere a los escritos de un sacerdote jesuita que visitó el sur de la provincia de Buenos Aires entre los años 1740 y 1750 . Este sacerdote relata varios tópicos de la vida de estas poblaciones, entre ellas la reverencia que prestaban a la sepultura de los muertos, destacando dos prácticas mortuorias. Por un lado, era costumbre entre los Araucanos argentinos y los Pampas que, al ocurrir una muerte, se elegía a la más distinguida de las mujeres para que llevara a cabo la evisceración y el descarne del cuerpo. Luego los restos eran sepultados hasta que se descomponían completamente o hasta que fueran removidos hacia la sepultura final. Advierte, además, que este último paso debía hacerse en el transcurso del año, pero que, a veces, se realizaba en menos de dos meses. Por otro lado, relata las costumbres de los pueblos Puelches y los Tehuelches, los cuales colocaban a los muertos en especies de catafalcos para "secarlos y blanquearlos al sol” (Latcham 1915: 144-146). Luego de esqueletizados, los empaquetaban en cueros y eran finalmente trasladados hasta el cementerio. A pesar de no poder determinar con exactitud el grupo de pertenencia de la población que dio origen al sitio MP, los relatos coinciden notablemente con las inferencias realizadas a partir del análisis efectuado.

\section{Conclusiones}

Entre las principales evidencias de acción antrópica registradas en los rasgos EA-1, H4, H6-1 y H7 del sitio MP se pueden citar el tipo de entierro y la manipulación precedente confirmada por la presencia de marcas de corte y de manchas de pigmentos. La tinción con ocre es leve y las manchas generalmente se presentan atenuadas por los diversos agentes tafonómicos.

Las condiciones de hallazgo de los entierros secundarios múltiples H4, H6-1 y H7 sugieren que los individuos inhumados dentro de cada uno de ellos habrían presentado distintos tiempos de descomposición, lo cual también habría influido de manera notoria en la manipulación de los cadáveres para la confección de los paquetes funerarios. De este modo, resulta complicado, incluso a partir del análisis del comportamiento funerario, proponer un rito o procedimiento estandarizado.
La presencia de hoyos de insectos también resulta una evidencia interesante, ya que plantea varias cuestiones. Desde dos posturas diametralmente opuestas, el sitio podría haber tenido tanto un origen sincrónico como uno diacrónico, con todos los matices intermedios posibles (i.e., desde entierros individuales que se fueron realizando con el transcurrir del tiempo, pasando por la inhumación múltiple sincrónica de un grupo de individuos o un rasgo, hasta un único evento de entierro general). Sin embargo, los fechados radiocarbónicos efectuados sugieren una sincronía entre los entierros múltiples. Por el momento, solo podríamos proponer que los entierros que conforman cada uno de los rasgos sí sean sincrónicos. Si fuera éste efectivamente el caso, la disposición de los huesos fue producto, por un lado, de la colocación intencional de los paquetes funerarios $\mathrm{y}$, por el otro, de la de diversos agentes y procesos post-depósito que incidieron en la posición final de los elementos, descartando la existencia de un acomodamiento post-depósito por parte de los individuos que habrían llevado a cabo las inhumaciones posteriores para efectivamente generar espacio y acomodarlos dentro de los rasgos.

Tal como se mencionó al principio, una serie de características relacionan al MP con otros sitios pampeanos y norpatagónicos del Holoceno Tardío final. Quizás, el rasgo principal sea el cambio en la cosmovisión que se vería reflejado en una variación en el uso del espacio (Martínez 2017). Es evidente que las poblaciones cazadoras-recolectoras del Holoceno Tardío compartieron programas mortuorios que implicaron numerosos estadios y un amplio espectro de actividades ritualizadas a lo largo del territorio que explotaban (Curtoni y Berón 2011; Flensborg et al. 2017; Martínez 2017; Martínez et al. 2012). Claramente es necesario continuar profundizando y sumando líneas de investigación en el análisis mortuorio para de este modo poder llegar a conclusiones más precisas acerca de las costumbres de estas sociedades de cazadores-recolectores.

Agradecimientos: Este trabajo fue desarrollado en el Laboratorio de Bioarqueología de la Universidad Nacional de Río Cuarto, Argentina. Los autores desean expresar su agradecimiento a las autoridades de la UNRC y de la provincia de La Pampa, y especialmente a la Dra. Ana Margarita Aguerre y al M.A. Osvaldo Mendonça. Asimismo desean expresar su profundo reconocimiento por las valiosas correcciones $\mathrm{y} / \mathrm{o}$ sugerencias aportadas por los expertos revisores y evaluadores de la revista. Cualquier error u omisión resultan de la exclusiva responsabilidad de los autores. 


\section{Referencias Citadas}

Acsádi, G. y J. Nemeskéri 1970. History of Human Life Span and Mortality. Akadémiai Kiadó, Budapest.

Baffi, E.I. y M. Berón 2000. Propuesta para la integración del conocimiento de sitios arqueológicos con restos humanos. El sitio Chenque I, provincia de La Pampa. Relaciones de la Sociedad Argentina de Antropología 25:145-158.

Barrientos, G. 1997. Nutrición y Dieta de las Poblaciones Aborígenes Prehispánicas del Sudeste de la Región Pampeana. Tesis Doctoral. Universidad Nacional de La Plata. La Plata.

Barrientos, G. y M.A. Gutiérrez 1996. Taphonomic and diagenetic processes of human bone remains in the Arroyo Seco 2 site, Pampean Region, Argentina. Trabajo presentado en el 61st Annual Meeting. Society for American Archaeology, New Orleans.

Barrientos, G. y M. Leipus 1997. Recientes investigaciones arqueológicas en el sitio Campo Brochetto (Pdo. de Tres Arroyos, Pcia. de Buenos Aires). En Arqueología Pampeana en la Década de los 90', editado por M.A. Berón y G. Politis, pp. 35-46. Museo de Historia Natural e INCUAPA, Facultad de Cs. Sociales, UNCPBA, San Rafael.

Barrientos, G., M.C. Del Papa y F.W. Oliva 2002. Historia pre y postdepositacional del entierro secundario del sitio laguna Los Chilenos I (Provincia de Buenos Aires). Relaciones de la Sociedad Argentina de Antropología 27:303-325.

Behrensmeyer, A.K. 1978. Taphonomic and ecologic information from bone weathering. Paleobiology 4 (2):150-162.

Bello, S.M., R. Wallduck, V. Dimitrijević, I. Živaljević y C.B. Stringer 2016. Cannibalism versus funerary defleshing and disarticulation after a period of decay: comparisons of bone modifications from four prehistoric sites. American Journal of Physical Anthropology 161 (4):722-743.

Bernardi, L. 2018. Los Cazadores-Recolectores del Médano Petroquímica (Colonia 25 de Mayo, Puelén, La Pampa). Caracterización de la Estructura y Composición del Conjunto por Medio de Marcadores Anatomofuncionales. Tesis Doctoral inédita, FCEFQyN, Universidad Nacional de Río Cuarto, Río Cuarto.

Berón, M. y G. Politis 1997. Arqueología Pampeana en la década de los 90', estado de las investigaciones y perspectivas. En Arqueología Pampeana en la década de los 90', editado por M. Berón y G. Politis, pp. 7-32. INCUAPA, Facultad de Ciencias Sociales de Olavarría, U.N.C.P.B.A. Museo de Historia Natural de San Rafael, San Rafael.

Berón, M. y L. Luna 2007. Modalidades de entierro en el sitio Chenque I. Diversidad y complejidad de los patrones mortuorios de los cazadores-recolectores pampeanos. En Arqueología en las Pampas, 1, editado por C. Bayón, I. González, N. Flegenheimer, A. Pupio y M. Frere, pp. 129-142. Sociedad Argentina de Antropología, Buenos Aires.

Berón, M., R.M. Di Donato y A. Markán 2012. Leather funerary packages: mortuary practices and differential preservation in a Late Holocene prehispanic cemetery (Pampean region, Argentina). Quaternary International 278:51-62.

Binford, L.R. 1971. Mortuary practices: their study and their potential. Memoirs of the Society for American Archaeology 25:6-29.

Binford, L.R. 1981. Bones: Ancient Men and Modern Myths. Academic Press, Nueva York.
Binford, L.R. 1984. Faunal Remains from Klasies River Mouth. Academic Press, Orlando.

Bökönyi, S. 1970. A new method for the determination of the number of individuals in animal bone material. American Journal of Archaeology 74 (3):291-292.

Bottini, M.C. 2017. Análisis Tafonómico y Caracterización Biológica de Cazadores Recolectores del Sudoeste de La Pampa: el Sitio Médano Petroquímica (Colonia 25 de Mayo, Puelén, La Pampa). Trabajo final de grado. Facultad de Cs. Exactas, Físico-Químicas y Naturales, Universidad Nacional de Río Cuarto, Río Cuarto.

Brickley, M. 2006. Rib Fractures in the Archaeological Record: A Useful Source of Sociocultural Information? International Journal of Osteoarchaeology 16:61-75.

Brooks, S. y J. Suchey 1990. Skeletal age determination based on the os pubis: a comparison of the Acsádi-Nemeskéri and Suchey-Brooks methods. Human Evolution 5:227-238.

Brown, J.A. 1981. The search for rank in prehistoric burials. En The Archaeology of Death, editado por R. Chapman, I. Kinnes, y K. Randsborg, pp. 25-37. Cambridge University Press, Cambridge.

Buikstra, J.E. y D.H. Ubelaker 1994. Standards for Data Collection from Human Skeletal Remains. Research Series No. 44. Arkansas Archeological Survey, Fayetteville.

Buckberry, J.L. y A.T. Chamberlain 2002. Age estimation from the auricular surface of the ilium: a revised method. American Journal of Physical Anthropology 119 (3):231-239.

Byrd, J.H. y J.L. Castner 2009. Forensic Entomology: The Utility of Arthropods in Legal Investigations, second ed. CRC press, Boca Ratón.

Carrera Aizpitarte, M.C., L. Luna, J. Paz, S. Gómez y P. Guiamet 2013. Médano La Enriqueta: un lugar de entierro de cazadores tardíos sobre el río Colorado (Dpto. Caleu Caleu, provincia de La Pampa). Revista del Museo de La Plata 13 (87):167-184.

Chaplin, R.E. 1971. The Study of Animal Bones from Archaeological Sites. Seminar Press, London.

Cúneo, E.M., A. Hajduk, P.S. Novellino y P.F. Azar 2016. Rescate de un cementerio de cazadores-recolectores prehispánicos: sitio Loma de la Lata (provincia del Neuquén, República Argentina). Intersecciones en Antropología 17 (3):315-325.

Curtoni, R. y M. Berón 2011. Perception, identity and meaning in the social and ritual construction of landscape: The Lihue Calel Hills, La Pampa, Argentina. Revista Chilena de Antropología 24:97-118.

Cushing, F.H. 1890. Preliminary Notes on the Origin, Working Hypothesis and Primary Researches of the Hemenway Southwestern Archaeological Expedition. En Compte-Rendu du Congres International des Americanistes de la Septieme Session 1888, editado por W. Kuhl, pp. 151-194, Berlin.

Dewbury, A.G. y N. Russell 2007. Relative frequency of butchering cutmarks produced by obsidian and flint: an experimental approach. Journal of Archaeological Science 34 (3):354-357.

Di Donato, R.M. 2007. La hora del Dermestes. Aportes de la entomología forense al análisis tafonómico de restos humanos. Sitio Chenque I, Parque Nacional Lihué Calel, provincia de La Pampa. En Tras las Huellas de la Materialidad. Resúmenes ampliados del XVI Congreso Nacional de Arqueología Argentina III, pp. 255-261. San Salvador de Jujuy. 
Duday, H. y M. Guillon 2006. Understanding the circumstances of decomposition when the body is skeletonized. En Forensic Anthropology and Medicine, editado por A. Schmitt, E. Cunha y J. Pinheiro, pp. 117-157. Humana Press Inc, Totowa.

Duday, H., F. Le Mort y A.M. Tillier 2014. Archaeothanatology and funeral archaeology. Application to the study of primary single burials. Anthropologie 52 (3):235-246.

Fisher, J.W. 1995. Bone surface modifications in zooarchaeology. Journal of Archaeological Method and Theory 2 (1):7-68.

Flensborg, G., G. Martínez, M. González y P. Bayala 2011. Revisión de los restos óseos humanos del sitio La Petrona (Transición Pampeano-Patagónica oriental, Argentina). Magallania 39 (1):179-191.

Flensborg, G., G. Martínez y P. Bayala 2017. Prácticas funerarias. Modalidades de inhumación y manejo de los cuerpos. En Arqueología de Cazadores-Recolectores del Curso Inferior del Río Colorado (Provincia de Buenos Aires, Argentina), Aportes al Conocimiento de las Ocupaciones Humanas PampeanoPatagónicas, editado por G. Martínez, pp. 175-191. Serie Monográfica 6. INCUAPA CONICET-UNICEN, Olavarría.

Frayer, D.W. 1997. Ofnet: evidence for a Mesolithic massacre. En Troubled Times: Violence and Warfare in the Past, editado por D. Martin y D.W. Frayer, pp. 181-216. Gordon and Breach, Amsterdam.

Fugassa, M.H., P.A. Martínez y N. Centeno 2008. Examen paleobiológico de sedimentos asociados a restos humanos hallados en el sitio arqueológico Alero Mazquiarán, Chubut, Argentina. Intersecciones en Antropología 9:03-09.

Gilbert, B.M. y T.W. McKern 1973. A method for aging the female os pubis. American Journal of Physical Anthropology 38 (1):31-38.

González, M. 2007. Estudios de interés tafonómico en los restos óseos humanos de Laguna Tres Reyes 1 (Partido de Adolfo Gonzales Chaves, provincia de Buenos Aires). Intersecciones en Antropología 8:215-233.

González, M. 2010. Huellas de corte y análisis contextual en restos óseos humanos de la cuenca inferior del río Colorado: implicaciones para el entendimiento de las prácticas mortuorias. En Mamül Mapu: Pasado y Presente Desde la Arqueología Pampeana, editado por M. Berón, L. Luna, M. Bonomo, C. Montalvo, C. Aranda y M. Carrera Aizpitarte, tomo I, pp. 227-237. Libros del Espinillo, Santa Rosa.

González, M. 2013. Procesos de formación y efectos tafonómicos en entierros humanos: el caso del sitio Paso Alsina 1 en Patagonia nororiental Argentina. Magallania 41 (1):133-154.

González, M. 2014. Procesos de formación y efectos tafonómicos en entierros humanos: el caso del sitio Arroyo Seco 2 en la región pampeana, Argentina. Relaciones de la Sociedad Argentina de Antropología 39 (1):175-202.

Haglund, W.D. 1992. Contribution of rodents to posmortem artifacts of bone and soft tissue. Journal of Forensic Sciences 37 (6):1459-1465.

Haglund, W.D. 1997a. Dogs and coyotes: Postmortem involvement with human remains. En Forensic Taphonomy. The Postmortem Fate of Human Remains, editado por W. D. Haglund y M. H. Sorg, pp. 367-381. CRC Press, Boca Ratón.

Haglund, W.D. 1997b. Rodents and human remains. En Forensic Taphonomy. The Postmortem Fate of Human Remains, editado por W. D. Haglund y M. H. Sorg, pp. 405-414. CRC Press, Boca Ratón.
Haglund, W.D., D.T. Reay y D.R. Swindler 1988. Tooth mark artifacts and survival of bones in animal scavenged human skeletons. Journal of Forensic Sciences 33 (4):985-997.

Henderson, J. 1987. Factors determining the state of preservation of human remains. En Death, Decay, and Reconstruction: Approaches to Archaeology and Forensic Science, editado por A. Boddington, A. Garland y R. Janaway, pp. 43-54. Manchester University Press, Manchester.

Hinsley, C.M. y D.R. Wilcox 1996. Frank Hamilton Cushing and the Hemenway Southwestern Archaeological Expedition, 1886-1889. University of Arizona Press, Tucson.

Hogg, A.G., Q. Hua, P.G. Blackwell, M. Niu, C.E. Buck, T.P. Guilderson y C.S. Turney 2013. SHCal13 Southern Hemisphere calibration, 0-50,000 years cal BP. Radiocarbon 55 (4):1889-1903.

Horwitz, L.K. y P. Smith 1988. The effects of striped hyaena activity on human remains. Journal of Archaeological Science 15 (5):471-481.

Huchet, J.B., F. Le Mort, R. Rabinovich, S. Blau, H. Coqueugniot y B. Arensburg 2013. Identification of dermestid pupal chambers on Southern Levant human bones: inference for reconstruction of Middle Bronze Age mortuary practices. Journal of Archaeological Science 40 (10):3793-3803.

Huchet, J.B., D. Deverly, B. Gutiérrez y C. Chauchat 2011. Taphonomic evidence of a human skeleton gnawed by termites in a Moche-civilisation grave at Huaca de la Luna, Peru. International Journal of Osteoarchaeology 21 (1):92-102.

Knüsel, C.J. y J. Robb 2016. Funerary taphonomy: an overview of goals and methods. Journal of Archaeological Science: Reports 10:655-673.

Latcham, R.E. 1915. Costumbres Mortuorias de los Indios de Chile y Otras Partes de América. Soc. Imprenta-litografía Barcelona, Santiago.

Laudet, F. y P.O. Antoine 2004. Des chambres de pupation de Dermestidae (Insecta:Coleoptera) sur un os de mammifère tertiaire (phosphorites du Quercy): implications taphonomiques et paléoenvironnementales. Geobios 37 (3):376-381.

Le Mort, F. y R. Rabinovich 1994. L'apport de l'étude taphonomique des restes humains à la connaissance des pratiques funéraires: exemple du site chalcolithique de Ben Shemen (Israël). Paléorient 20 (1):69-98

Lovejoy, C., R. Meindl, T. Pryzbeck y R. Mensforth 1985. Chronological metamorphosis of the auricular surface of the ilium: A new method for the determination of adult skeletal age at death. American Journal of Physical Anthropology 68:15-28.

Lovell, N.C. 1997. Trauma analysis in paleopathology. Yearbook of Physical Anthropology 40:139-170.

Luna, L., E.I. Baffi y M. Berón 2004. El rol de las estructuras formales de entierro en el proceso de complejización de las poblaciones cazadoras-recolectoras del Holoceno tardío. En Aproximaciones Contemporáneas a la Arqueología Pampeana, editado por G. Martínez, M. Gutierrez, R. Curtoni, M. Berón y P. Madrid, pp. 61-73. Facultad de Ciencias Sociales, UNCPBA, Olavarría.

Lyman, R.L. 1994. Vertebrate Taphonomy. Cambridge Manuals in Archaeology. Cambridge University Press, Cambridge.

Madrid,P.y G. Barrientos 2000. Laestructura del registro arqueológico Laguna Tres Reyes 1 (provincia de Buenos Aires): nuevos datos para la interpretación del poblamiento humano del sudeste de la Región Pampeana a inicios del Holoceno Tardío. Relaciones de la Sociedad Argentina de Antropología XXV:179-206. 
Mariano, C.I. 2011. Prácticas mortuorias y registro bioarqueológico en la costa rionegrina del golfo San Matías, Argentina. Intersecciones en Antropología 12 (1):17-30.

Martin, L.D. y D.L. West 1995. The recognition and use of dermestid (Insecta, Coleoptera) pupation chambers in paleoecology. Palaeogeography, Palaeoclimatology, Palaeoecology 113 (2-4):303-310.

Martínez, G. 2006. Arqueología del curso medio del río Quequén Grande: estado actual y aportes a la arqueología de la región pampeana. Relaciones de la Sociedad Argentina de Antropología 31:249-275.

Martínez, G. 2008. Arqueología del curso inferior del río Colorado: estado actual del conocimiento e implicaciones para la dinámica poblacional de cazadores recolectores pampeanopatagónicos. Revista de Arqueología 3:71-92.

Martínez, G. 2010. Entierros humanos en lugares sagrados y domésticos durante el Holoceno tardío: El registro bioarqueológico del curso inferior del río Colorado (Provincia de Buenos Aires, Argentina). Werkén 13:145-161.

Martínez, G. 2017. Conclusiones. En Arqueología de CazadoresRecolectores del Curso Inferior del Río Colorado (Provincia de Buenos Aires, Argentina), Aportes al Conocimiento de las Ocupaciones Humanas Pampeano-Patagónicas, editado por G. Martínez, pp. 298-311. Serie Monográfica 6. INCUAPA CONICET-UNICEN, Olavarría.

Martínez, G.A. y M.J. Figuerero Torres 2000. Sitio arqueológico La Petrona (Partido de Villarino, provincia de Buenos Aires) Análisis de las modalidades de entierro en el área sur pampeana. Relaciones de la Sociedad Argentina de Antropología 25:227-247.

Martínez, G., P. Bayala, G. Flensborg y R. López 2006. Análisis preliminar de los entierros humanos del sitio Paso Alsina 1 (Partido de Patagones, Provincia de Buenos Aires). Intersecciones en Antropología 7:95-108.

Martínez, G., G. Flensborg y P.D. Bayala 2012. Human corpse manipulation and the body as symbol: A case study from the Eastern Pampa-Patagonia transition (Argentina) during the Final Late Holocene. Journal of Anthropological Archaeology 31 (2):215-226.

Masset, C. 1993. Les Dolmens: Sociétés Néolithiques, Practiques Funéraires: Les Sepultures Collectives d'Europe Occidentale. Editions Errance, Paris.

Massigoge, A. 2009. Arqueología de los Cazadores-Recolectores del Sudeste de la Región Pampeana: Una Perspectiva Tafonómica. Tesis Doctoral. Facultad de Ciencias Naturales y Museo. Universidad Nacional de La Plata. La Plata.

Massigoge, A., M. González, C. Kaufmann y M.A. Gutiérrez 2010. Observaciones actualísticas sobre meteorización ósea en restos esqueletales de guanaco. En Mamül Mapu: Pasado y Presente desde la Arqueología Pampeana, editado por M. Berón, L. Luna, M. Bonomo, C. Montalvo, C. Aranda y M. Carrera Aizpitarte, pp. 215228. Editorial Libros del Espinillo, Santa Rosa.

Mazzanti, D. y C. Quintana 2001. Cueva Tixi: cazadores y recolectores de las sierras de Tandilia Oriental. Geología, Paleontología y Zooarqueología. Laboratorio de Arqueología, UNMdP, Publicación Especial 1, Mar del Plata.

Mazzanti, D.L., C.A. Quintana y F.M. Porto López 2014. Los cazadores-Recolectores posteriores: una larga historia. En Historias Milenarias Pampeanas: Arqueología de las Sierras de Tandilia, editado por D.L. Mazzanti y C.A. Quintana, pp. 33-44. Ed. Área Cuatro, Mar del Plata.

Mazzia, N., C. Scabuzzo y R. Guichón 2004. Sobre cráneo, pelvis y otros huesos. Entierros humanos en el sitio El Guanaco. En Aproximaciones
Contemporáneas a la Arqueología Pampeana. Perspectivas Teóricas, Metodológicas, Analíticas y Casos de Estudio, editado por M. Martínez, M.A. Gutiérrez, R. Curtoni, M. Berón y P. Madrid, pp. 293-304 Universidad Nacional del Centro de la Provincia de Buenos Aires, Facultad de Ciencias Sociales, Olavarría.

McKern, T. y T. Stewart 1957. Technical Report EP-45. Skeletal Age Changes in Young American Males. Headquarters Quartermaster Research and Engineering Command, Natick.

Meindl, R. y C. Lovejoy 1989. Age changes in the pelvis: implications for paleodemography. En Age Markers in the Human Skeleton, editado por M. Isçan, pp. 137-168. C.C. Thomas Publisher, Springfield.

Mendonça, O.J., A.M. Aguerre, M.A. Bordach, M. Ammann, M. Arrieta, M.C. Croatto y L.M. Pera 2010. Inclusiones funerarias y dimensiones sociales del comportamiento mortuorio en el Médano Petroquímica, Departamento Puelén, Provincia de La Pampa. En Mamül Mapu: Pasado y Presente Desde la Arqueología Pampeana, editado por M. Berón, L. Luna, M. Bonomo, C. Montalvo, C. Aranda y M. Carrera Aizpitarte, pp. 227-237. Libros del Espinillo, Santa Rosa.

Micozzi, M.S. 1991. Postmortem Change in Human and Animal Remains. A Systematic Approach. Charles C. Thomas Publisher, Springfield.

Mondini, M. 2003. Formación del Registro Arqueofaunístico en Abrigos Rocosos de la Puna Argentina. Tafonomía de Carnívoros. Tesis Doctoral. Facultad de Filosofía y Letras, Universidad de Buenos Aires, Buenos Aires.

Peacock, E.R. 1993. Adults and larvae of hide, larder and carpet beetles and their relatives (Coleoptera: Dermestidae) and of derodontid beetles (Coleoptera: Derodontidae). En Handbooks for the Identification of British Insects, editado por W.R. Dolling, Vol 5 , No 3, pp. 1-144. Royal Entomological Society of London, London.

Phenice, T. 1969. A newly developed visual method of sexing in the os pubis. American Journal of Physical Anthropology 30:297-301.

Politis, G., G. Barrientos y C. Scabuzzo 2014. Los entierros humanos de Arroyo Seco 2. En Estado Actual de las Investigaciones en el Sitio Arqueológico Arroyo Seco 2, editado por G. Politis, M.A. Gutiérrez y C. Scabuzzo, pp. 329-369. Serie Monográfica 5. INCUAPA-CONICET-UNICEN, Olavarría.

Roksandic, M. 2002. Position of skeletal remains as a key to understanding mortuary behavior. En Advances in Forensic Taphonomy: Method, Theory, and Archaeological Perspectives, editado por W.D. Haglund y M.H. Sorg, pp. 99-117. CRC Press, Boca Ratón.

Saxe, A.A. 1971. Social dimensions of mortuary practices in a Mesolithic population from Wadi Haifa, Sudan. Memoirs of the Society for American Archaeology 25, 39-57.

Scabuzzo, C. y G. Politis 2006. Early Holocene secondary burials in the Pampas of Argentina. Current Research of the Pleistocene 23:64-66.

Scabuzzo, C. y G. Politis 2011. Los entierros secundarios del Holoceno temprano y medio en la región pampeana. Nuevos datos del sitio Arroyo Seco 2. Cazadores Recolectores del Cono Sur. Revista de Arqueología 4:135-155.

Stodder, A.L.W. 2008. Taphonomy and the nature of archaeological assemblages. En Biological Anthropology of the Human Skeleton editado por M.A. Katzenberg y S.R. Saunders, pp. 71-114. WileyLiss, New York

Tavarone, A., M. Dantas y M. Fabra 2016. Tafonomía de restos óseos humanos arqueológicos en ambientes lacustres. El caso del sitio El Diquecito (Laguna Mar Chiquita, Córdoba, Argentina). Cuadernos del 
Instituto Nacional de Antropología y Pensamiento Latinoamericano 25 (2):191-210.

Todd, T. 1921a. Age changes in the pubic bone. I: The male white pubis. American Journal of Physical Anthropology 3:285334.

Todd, T. 1921b. Age changes in the pubic bone. III: The pubis of the white female. IV: the pubis of the female white-negro hybrid. American Journal of Physical Anthropology 4:1-70.

Todd, L. y G. Frison 1992. Reassembly of bison skeletons from the Horner site: A study in anatomical refitting. En Piecing Together the Past: Applications of Refitting Studies in Archaeology, editado por J. Hofman, y G. Enloe, pp. 63-82. BAR International Series 579, Oxford.

Ubelaker, D.H. 1974. Reconstruction of Demographic Profiles from Ossuary Skeletal Samples. Smithsonian Contributions to Anthropology. $\mathrm{N}^{\circ}$ 18. Smithsonian Institution Press, Washington DC.
Ubelaker, D.H. 1981. The Ayalan Cemetery: A Late Integration Period Burial Site on the South Coast of Ecuador. Smithsonian Contributions to Anthropology, No. 29, Washington DC.

Villa, P. y E. Mahieu 1991. Breakage patterns of human long bones. Journal of human evolution 21 (1):27-48.

Walker, P. 2001. A Bioarchaeological Perspective on the History of Violence. Annual Review of Anthropology 30 (1):573-596.

Walker, P. 2005. Greater sciatic notch morphology: sex, age, and population differences. American Journal of Physical Anthropology 127 (4):385-391.

White, T.D. 1992. Prehistoric Cannibalism at Mancos 5MTUMR-2346. Princeton University Press, Princeton.

White, T.D. y N. Toth 1989. Engis: preparation damage, not ancient cutmarks. American Journal of Physical Anthropology 78:361-68. 
